\title{
Bioaccumulation and Toxicity of Selenium during a Life-Cycle Exposure with Desert Pupfish (Cyprinodon macularius)
}
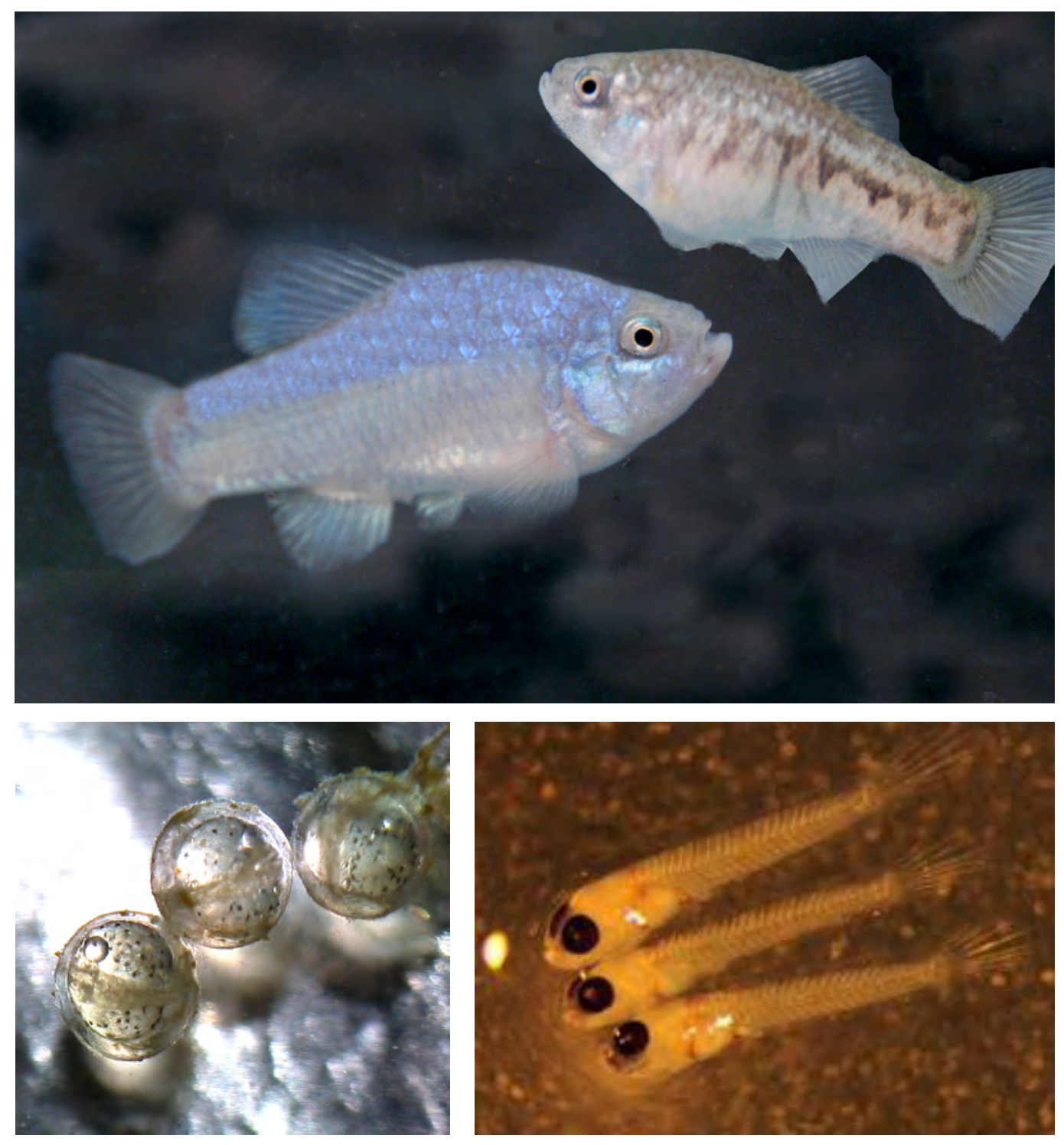

Scientific Investigations Report 2012-5033 
Cover. Photographs of desert pupfish. Adult male and female (top); eggs (lower left); and larvae (bottom right). 


\section{Bioaccumulation and Toxicity of Selenium during a Life-Cycle Exposure with Desert Pupfish (Cyprinodon macularius)}

By J.M. Besser, W.G. Brumbaugh, D.M. Papoulias, C.D. Ivey, J.L Kunz, M. Annis, and C.G. Ingersoll

Scientific Investigations Report 2012-5033 


\title{
U.S. Department of the Interior \\ KEN SALAZAR, Secretary \\ U.S. Geological Survey \\ Marcia K. McNutt, Director
}

\author{
U.S. Geological Survey, Reston, Virginia: 2012
}

For more information on the USGS - the Federal source for science about the Earth, its natural and living resources, natural hazards, and the environment, visit http://www.usgs.gov or call 1-888-ASK-USGS.

For an overview of USGS information products, including maps, imagery, and publications,

visit http://www.usgs.gov/pubprod

To order USGS information products, visit http://store.usgs.gov

Any use of trade, product, or firm names is for descriptive purposes only and does not imply endorsement by the U.S. Government.

Although this report is in the public domain, permission must be secured from the individual copyright owners to reproduce any copyrighted materials contained within this report.

Suggested citation:

Besser, J.M., Brumbaugh, W.G., Papoulias, D.M., Ivey, C.D., Kunz, J.L, Annis, M. and Ingersoll, C.G., 2012, Bioaccumulation and toxicity of selenium during a life-cycle exposure with desert pupfish (Cyprinodon macularius): U.S. Geological Survey Scientific Investigations Report 2012-5033, 30 p. with appendixes. 


\section{Contents}

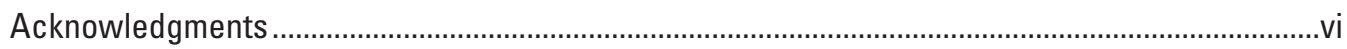

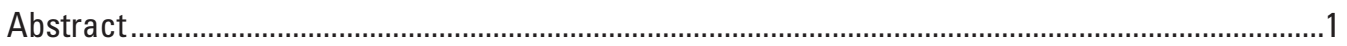

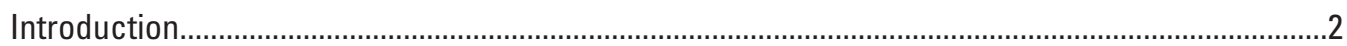

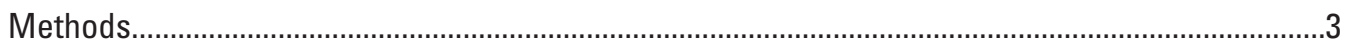

Task 1-Oligochaete Selenium Dosing .................................................................................

General Test Conditions .............................................................................................

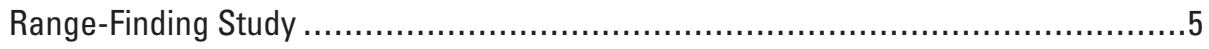

Bioaccumulation Kinetics Study ..............................................................................

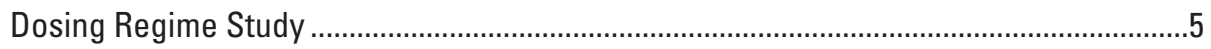

Task 2-Selenium Bioaccumulation and Toxicity in Juvenile and Adult Pupfish .....................5

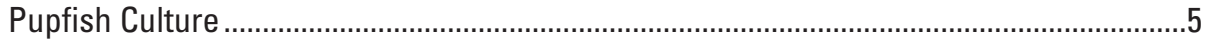

Preparation of Selenium-Dosed Diets.............................................................................. 5

Pupfish Selenium Exposures ................................................................................................

Task 3-Effects of Selenium on Pupfish Reproduction..............................................................6

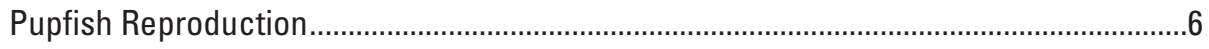

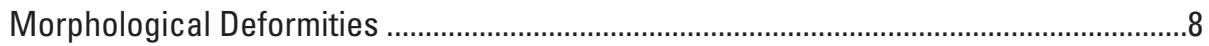

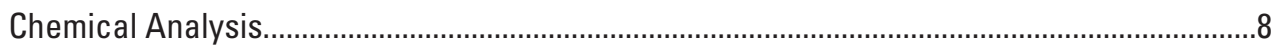

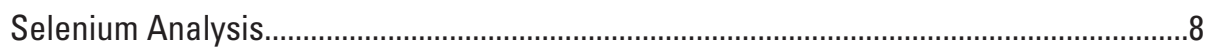

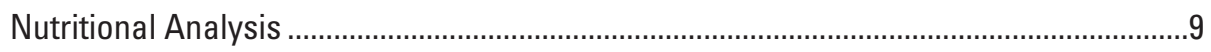

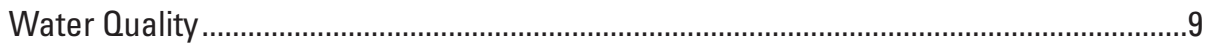

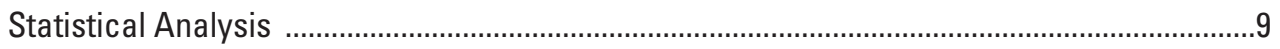

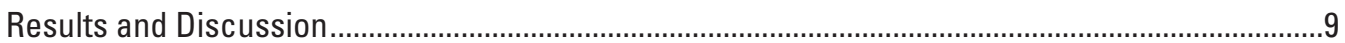

Selenium Bioaccumulation by Oligochaetes ........................................................................

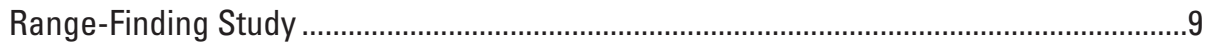

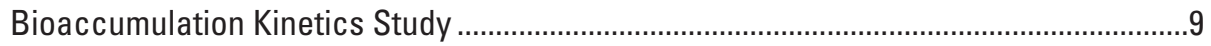

Dosing Regime Study .........................................................................................................

Selenium Concentrations in Water, Diets, and Pupfish Tissues .................................................10

Selenium Exposure Levels .........................................................................................10

Pupfish Selenium Bioaccumulation...............................................................................11

Toxicity of Selenium to Pupfish...........................................................................................

Survival and Growth of Juveniles and Adults ............................................................13

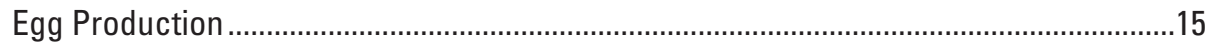

Egg Hatching and Larval Survival ..............................................................................18

Morphological Deformities ........................................................................................ 19

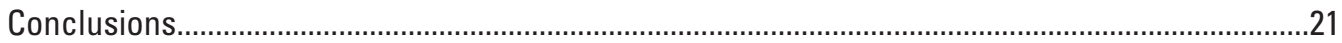

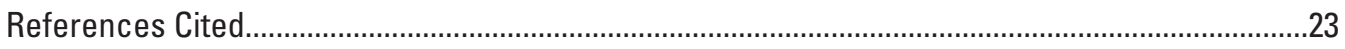

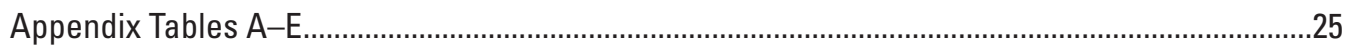




\section{Figures}

1. Graphs showing effects of dietary selenium levels and feeding rations on oligochaetes in a 13-day range-finding test.....

2. Graphs showing selenium bioaccumulation by oligochaetes fed two rations of Se-dosed yeast diets in a 27-day bioaccumulation study....

3. Graphs showing biomass of oligochaetes fed two rations of selenium-dosed yeast in a 27-day bioaccumulation study

4. Graphs showing selenium bioaccumulation by oligochaetes fed selenium-dosed yeast in two exposure regimes

5. Graphs showing selenium bioaccumulation in desert pupfish whole-body and egg samples during life-cycle selenium exposure: controls and five selenium levels (Se-1 through Se-5)

6. Graph showing selenium bioaccumulation in adult male and adult female desert pupfish and eggs from the main reproduction study.

7. Graphs showing egg production by desert pupfish during life-cycle selenium exposure.

8. Graphs showing variation in desert pupfish egg production among replicate spawning groups

9. Graph showing differences in desert pupfish egg production between selenium treatments and controls by sampling date.

10. Graph showing egg hatching and larval survival during the main reproduction study.

11. Photographs showing normal and deformed pupfish larvae

12. Graph showing frequency of deformities in pupfish larvae from preliminary and main reproduction studies

\section{Tables}

1. Total selenium (Se) and selenomethionine (SeMet) concentrations in water, sediment, diet items, and fish from desert pupfish habitats in the Imperial Valley, California

2. Exposure groups, endpoints, and sampling schedule for a life-cycle selenium toxicity test with desert pupfish

3. Total selenium (Se) and selenomethionine (SeMet) concentrations in water, oligochaete diets, and pupfish tissue during life-cycle Se exposures.

4. First-order exponential models of selenium bioaccumulation by oligochaetes (from selenized yeast) and desert pupfish (from selenium-dosed oligochaetes)...........12

5. Variation of total selenium concentrations in oligochaetes using different exposure regimes

6. Survival and growth of pupfish during a life-cycle selenium exposure .16

7. Summary of repeated-measures ANOVA and least-squares means comparisons for effects of selenium on pupfish egg production.

8. Relative frequency of types of deformities observed in F1 pupfish larvae .....................20

9. Summary of pupfish toxicity endpoints and selenium exposure levels ...........................22 


\section{Appendix Tables A-E}

A. Test conditions for dosing oligochaete diets with selenium ..........................................26

B. Test conditions for life-cycle selenium exposure with desert pupfish..............................27

C. Nutritional characteristics of oligochaete diets from pupfish life-cycle

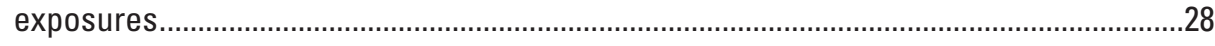

D. Summary of water quality during pupfish life-cycle exposure ..........................................29

E. Egg production by pupfish during the main reproduction study ....................................30

\section{Conversion Factors and Abbreviations}

SI to Inch/Pound

\begin{tabular}{lcl}
\hline \multicolumn{1}{c}{ Multiply } & By & \multicolumn{1}{c}{ To obtain } \\
\hline centimeter (cm) & Length & \\
millimeter (mm) & 0.3937 & inch (in) \\
meter (m) & .03937 & inch (in.) \\
meter (m) & 3.281 & foot (ft) \\
\hline & 1.094 & yard (yd) \\
\hline liter (L) & Volume & \\
liter (L) & 33.82 & ounce, fluid (fl. oz) \\
liter (L) & 2.113 & pint (pt) \\
liter (L) & 1.057 & quart (qt) \\
liter (L) & .2642 & gallon (gal) \\
\hline & 61.02 & cubic inch (in $\left.{ }^{3}\right)$ \\
\hline gram (g) & Mass & \\
kilogram (kg) & 0.03527 & ounce, avoirdupois (oz) \\
\hline
\end{tabular}

Temperature in degrees Celsius $\left({ }^{\circ} \mathrm{C}\right)$ may be converted to degrees Fahrenheit $\left({ }^{\circ} \mathrm{F}\right)$ as follows:

$$
{ }^{\circ} \mathrm{F}=\left(1.8 \times{ }^{\circ} \mathrm{C}\right)+32
$$

Concentrations of chemical constituents in water are given either in milligrams per liter $(\mathrm{mg} / \mathrm{L})$ or micrograms per liter ( $\mu \mathrm{g} / \mathrm{L})$. 


\section{Acknowledgments}

This publication serves as a final report to the Imperial Irrigation District, Imperial, California and the U.S. Fish and Wildlife Service, Carlsbad California (Project Number 8100000392, dated November 3, 2004; amended October 22, 2007). Scott Sobiech, Carol Roberts, and Sharon Taylor of the U.S. Fish and Wildlife Service; Bruce Wilcox, Tina Anderholt-Shields, and John Eckhardt of Imperial Irrigation District; and Harry Ohlendorf and Jeff Tupen of CH2M-Hill assisted with study planning and execution, and data interpretation. Harry Ohlendorf also reviewed the draft manuscript. Lili Wan of the University of Missouri developed selenomethionine (SeMet) analytical methodology and conducted analyses of SeMet in tissue samples.

Many personnel of U.S. Geological Survey made valuable contributions to this work. Eugene Greer, David Whites, and Ryan Warbritton maintained cultures of pupfish and oligochaetes. Doug Hardesty, Eric Brunson, and Jamie Hughes assisted with preparation of seleniumdosed oligochaetes and conducting pupfish exposures. Mike Walther and Jesse Arms assisted with selenium analyses. Mike Saiki and Tom May provided valuable pre-publication information from their selenium monitoring project in Imperial Valley, California. Barbara Martin, Kevin Buhl, and Chris Mebane reviewed earlier drafts of this manuscript. 


\title{
Bioaccumulation and Toxicity of Selenium during a Life-Cycle Exposure with Desert Pupfish (Cyprinodon macularius)
}

\author{
By J.M. Besser, W.G. Brumbaugh, D.M. Papoulias, C.D. Ivey, J.L Kunz, M. Annis, and C.G. Ingersoll
}

\section{Abstract}

Populations of desert pupfish (Cyprinodon macularius; pupfish), a federally-listed endangered species, inhabit irrigation drains in the Imperial Valley agricultural area of southern California. These drains have varying degrees of selenium (Se) contamination of water, sediment, and aquatic biota. Published Se toxicity studies suggest that these levels of Se contamination may pose risk of chronic toxicity to Se-sensitive fish, but until recently there have been no studies of the chronic toxicity of Se to desert pupfish.

A life-cycle Se exposure with pupfish was conducted to estimate dietary and tissue thresholds for toxic effects of Se on all life stages. The dietary exposure was based on live oligochaete worms (Lumbriculus variegatus) dosed with Se by a laboratory food chain based on selenized yeast. Oligochaetes readily accumulated Se from mixtures of selenized and control yeasts. The protocol for dosing oligochaetes for pupfish feeding studies included long-term (at least 28 days) feeding of a low-ration of yeast mixtures to large batches of oligochaetes. Oligochaetes were dosed at five Se levels in a 50-percent dilution series. Pupfish were simultaneously fed Se-dosed oligochaetes and exposed to a series of Se concentrations in water (consisting of 85 percent selenate and 15 percent selenite) to produce exposures that were consistent with Se concentrations and speciation in pupfish habitats. The nutritional characteristics of oligochaete diets were consistent across the range of oligochaete Se concentrations tested.

The life-cycle exposure started with laboratory-cultured juvenile pupfish that were exposed to Se through sexual maturation and reproduction (150 days; F0 exposure). The Se exposure continued with eggs, larvae, and juveniles produced by Se-exposed parents (79 days; F1 exposure). Selenium exposure (water and diets), Se bioaccumulation (whole-body and eggs), and toxicity endpoints (juvenile and adult survival and growth; egg production and hatching success, larval survival and deformities) were documented throughout the life-cycle study.

Selenium concentrations in water (as much as 52 micrograms per liter $[\mu \mathrm{g} / \mathrm{L}]$ ) and diets (as much as 53 micrograms per gram $[\mu \mathrm{g} / \mathrm{g}]$, on a dry weight basis) bracketed concentrations reported in pupfish habitats. Juvenile F0 pupfish rapidly accumulated Se and bioaccumulation models indicated that pupfish had reached more than 97 percent of maximum whole-body Se concentrations by the time they reached reproductive maturity. Adult pupfish accumulated whole-body Se concentrations that averaged about 40 percent of those in the oligochaete diets. Selenium concentrations in eggs and F1 juveniles were similar to or slightly greater than Se concentrations in F0 adults. Juvenile F0 pupfish contained selenomethionine fractions (62-71 percent of whole-body Se) greater than the average reported for wild pupfish from the Imperial Valley (53 percent).

Selenium exposure had minimal effects on survival or growth of juvenile and adult pupfish. There was evidence of toxic effects on pupfish in the highest Se treatment (Se-5), including reduced growth of F0 and F1 juvenile pupfish (17-21 percent less than controls) on some sampling dates. These growth reductions did not persist to subsequent sampling dates, but reduced growth of F1 pupfish in the Se-5 treatment was associated with reduced survival (12 percent less than controls).

Egg production was reduced in most Se treatments during a 12-week reproduction study. Egg production was greatest in the controls and decreased with increasing Se exposure, reaching a minimum (51 percent less than controls) in the $\mathrm{Se}-4$ treatment, but egg production was reduced by only 24 percent in the Se-5 treatment, a lesser reduction than in other $\mathrm{Se}$ treatments except $\mathrm{Se}-1$. There was no statistically significant overall effect of Se treatment on mean pupfish egg production, reflecting large variation among replicates and among sampling dates. However, comparisons of daily mean egg production for 23 sampling dates indicated that egg production in each of 5 Se treatments was significantly less than controls on multiple (3-7) sampling dates, but no mean for any Se treatment was significantly greater than controls on any date. Significant reductions in daily egg production occurred mainly during the middle of the study and egg production increased in several Se treatments during the final 2 weeks of the study. These results suggest that pupfish egg production, although a highly variable endpoint, was adversely affected by elevated Se exposure. 
Neither egg hatching success nor survival of F1 larvae indicated clear evidence of Se toxicity. Egg hatching success did not differ significantly among treatments, with means ranging from 84-91 percent. The frequency of morphological deformities (primarily spinal deformities) was greater in larvae 10 days post-fertilization (dpf) from a preliminary reproduction study than in older larvae (14 dpf) from the main reproduction study. The frequency of larval deformities was generally greater in $\mathrm{Se}$ treatments than controls, but mean frequencies did not differ significantly among treatments. Survival of F1 larvae to $21 \mathrm{dpf}$ was not reduced significantly by parental Se exposure, but the Se -5 treatment had the lowest larval survival ( 84 percent), and lowest combined egg hatching and larval survival (76 percent).

Results of the Se treatments indicate that pupfish were insensitive to Se toxicity through most of their life cycle. Consistent toxic effects on survival and growth of juvenile and adult pupfish (defined as at least 10 percent reduction compared to controls) occurred only in treatment $\mathrm{Se}-5$, which had a mean dietary Se concentration of $52 \mu \mathrm{g} / \mathrm{g}$ and a mean pupfish whole-body Se concentration of $27 \mu \mathrm{g} / \mathrm{g}$. These apparent toxicity thresholds for growth and survival rank among the least sensitive chronic Se toxicity values reported for nonreproductive endpoints in freshwater fish. Comparisons of these thresholds to surveys of Se concentrations in the Imperial Valley suggest that risks of Se toxicity are low in pupfish habitats. The dietary threshold was about twice as high as the greatest mean Se concentrations reported in midge larvae from seven sites in the Imperial Valley. Whole-body thresholds were greater than mean whole-body Se concentrations reported for field-collected pupfish from three sites and for the sailfin molly (Poecilia latipinna), a potential bioaccumulation surrogate for pupfish, from seven sites.

Reduced egg production, although highly variable, was the most sensitive response of pupfish to Se exposure. Toxic effects on egg production (reductions of 24-51 percent relative to controls) occurred in the four highest Se treatments, corresponding to reproductive toxicity thresholds of $7.3 \mu \mathrm{g} / \mathrm{g}$ for Se in diet, $3.4 \mu \mathrm{g} / \mathrm{g}$ in pupfish (whole body), and $4.4 \mu \mathrm{g} / \mathrm{g}$ in pupfish eggs. These thresholds are substantially lower than published Se toxicity values for reproductive effects in other freshwater fish (for example, 17-24 $\mu \mathrm{g} / \mathrm{g}$ in eggs). Reduced egg production has not been reported as a sensitive endpoint in Se toxicity studies, although abnormal ovarian development has been reported in Se-exposed fish, and reduced egg production has been reported as a sensitive response of other Cyprinodon pupfish to other environmental stressors.

Selenium concentrations in tissues of pupfish, mollies, and diet items from Imperial Valley sites frequently exceeded concentrations associated with reduced pupfish egg production in the laboratory study. Reduced egg production may limit the ability of pupfish populations to persist and recover in Se-contaminated habitats in the Imperial Valley and elsewhere in their limited range. However, these apparent risks of Se toxicity are not supported by recent surveys of desert pupfish populations in the Imperial Valley. These surveys indicated that desert pupfish made up a small, but variable, component of fish communities in Imperial Valley habitats, including sites with increased levels of Se exposure, and that pupfish distribution and population density indicated no clear relationships with Se concentrations in diets or fish tissues. Additional studies could determine the role of egg production in the maintenance and recovery of desert pupfish populations in Se-contaminated habitats.

\section{Introduction}

Populations of desert pupfish (Cyprinodon macularius; pupfish), a federally-listed endangered species, inhabit irrigation drains in the Imperial Valley agricultural area of southern California and adjacent shoreline habitats of the Salton Sea (Martin and Saiki, 2005; Saiki and others, 2011c). Evidence of selenium (Se) contamination of water, sediment, and aquatic organisms in these habitats has led to concern that Se toxicity may adversely affect pupfish populations. Saiki and others (2010, 2011a) monitored Se concentrations in seven irrigation drains in the Imperial Valley, including sites inhabited by pupfish, during 2006-2008 and reported site means for Se concentrations in water ranging from 1.5 to 22 micrograms per liter $(\mu \mathrm{g} / \mathrm{L})$ and site means for Se concentrations in midge larvae (Chironomidae) ranging from 3.5 to 25 micrograms per gram $(\mu \mathrm{g} / \mathrm{g})$ (all tissue Se concentrations reported on a dry weight basis; table 1). Published Se toxicity studies suggest that these levels of Se contamination may pose a risks of chronic toxicity to Se-sensitive fish (DeForest and Adams, 2011; Janz and others, 2010; Lemly, 1993a), but there have been no studies of the chronic toxicity of Se to pupfish.

Table 1. Total selenium (Se) and selenomethionine (SeMet) concentrations in water, sediment, diet items, and fish from desert pupfish habitats in the Imperial Valley, California.

[Total Se data (except desert pupfish data) are grand means (56-126 samples per sample type) and ranges of site means for 7 sites sampled by Saiki and others (2010). All data for desert pupfish (27 samples for total Se; 23 samples for SeMet) and SeMet data for other sample types ( 9 samples per type) are from 3 sites sampled by Saiki and others (2011c); nd, not determined; <, less than]

\begin{tabular}{lccc}
\hline \multicolumn{1}{c}{ Sample type } & $\begin{array}{c}\text { Total Se, } \\
\text { grand mean }\end{array}$ & $\begin{array}{c}\text { Total Se, } \\
\text { range of site } \\
\text { means }\end{array}$ & $\begin{array}{c}\text { SeMet } \\
\text { fraction } \\
\text { (percent), } \\
\text { mean }\end{array}$ \\
\hline \multicolumn{4}{c}{ Filtered Se (micrograms per liter) } \\
\hline Water & 5.6 & $1.5-22$ & nd \\
\hline \multicolumn{4}{c}{ Sediment total Se (micrograms per gram dry weight) } \\
\hline Sediment & 1.4 & $0.46-7.0$ & nd \\
\hline \multicolumn{4}{c}{ Diet total Se (micrograms per gram dry weight) } \\
\hline Organic detritus & 5.5 & $2.1-17$ & 6.7 \\
Filamentous algae & 2.2 & $2.0-4.6$ & 26 \\
Net plankton & 2.4 & $.15-19$ & $<7.5$ \\
Midge larvae & 6.5 & $3.5-25$ & 44 \\
\hline \multicolumn{4}{c}{ Fish whole-body Se (micrograms per gram dry weight) } \\
\hline Mosquitofish & 6.8 & $5.3-17$ & 45 \\
Sailfin molly & 6.9 & $4.3-20$ & 36 \\
Desert pupfish & 4.5 & $4.0-5.3$ & 53 \\
\hline \multicolumn{4}{l}{}
\end{tabular}


A series of laboratory studies was conducted to determine dietary and tissue-based thresholds for toxic effects of Se on pupfish, with special consideration for conditions in Imperial Valley pupfish habitats. A previous study reported acute toxicity tests with pupfish exposed to Se species in water and demonstrated the feasibility of conducting laboratory chronic toxicity tests with juvenile pupfish (Besser and others, 2004). However, dietary Se is the predominant exposure route for bioaccumulation and toxicity of Se in freshwater fish and chronic toxic effects on reproduction and early life stages are the most sensitive responses to chronic Se exposure (Janz and others, 2010). A conservative evaluation of Se risks to pupfish requires a realistic Se exposure regime, including exposure to Se concentrations and Se species in water and diet that are representative of Se exposure in pupfish habitats. Such a study also requires a long exposure period, which would ensure equilibration of Se concentrations in target organs and allow evaluation of all potentially sensitive life stages of pupfish.

Invertebrates from habitats associated with irrigated agriculture in California accumulate Se concentrations substantially greater than background levels, with substantial portions of the Se burden occurring as the Se-amino acid, selenomethionine (SeMet), rather than the inorganic Se species, selenate and selenite, that predominate in contaminated waters (Fan and others, 2002; Saiki and others, 2010, 2011a) (table 1). Experimental diets used for studies of the toxicity of Se-contaminated diets of fish have differed widely, ranging from diets containing Se-rich tissues of aquatic biota from Secontaminated habitats (Hamilton and others, 1990; Hamilton and others, 2002), to direct spiking of SeMet into prepared diets (Coyle and others, 1991; Lemly, 1993b), to processing of aqueous Se through laboratory food-chains (McIntyre and others, 2008; Ogle and Knight, 1989). Each of these approaches has disadvantages, including lack of realism (direct Se spiking), possible interactions with other contaminants (fieldcollected tissues), and technical complexity (laboratory food webs). The studies reported here focused on preparing a pupfish diet of live oligochaete worms (Lumbriculus variegatus), dosed with Se using a diet containing selenized yeast, which would contain Se concentrations and SeMet content consistent with invertebrates from pupfish habitats.

Laboratory-cultured pupfish were fed Se-dosed oligochaetes and exposed to aqueous Se throughout a 30-week life-cycle exposure that started with juveniles an adults of the parental generation (F0 exposure; 150 days) and continued with larvae and juveniles of the offspring (F1 exposure; 79 days) (table 2). Selenium exposure (Se concentrations in water and diets; Se bioaccumulation in whole-body samples and eggs) and toxic effects (juvenile and adult survival and growth; egg production and hatching success; and larval survival and deformities) were documented throughout the life-cycle exposure, which was conducted as three tasks:

Task 1 characterized Se bioaccumulation by oligochaetes fed diets of Se-dosed yeast. This task developed a method for preparing diets of live invertebrates with consistent Se concentrations and SeMet content. Diets of live, laboratory-cultured oligochaetes dosed with trace elements have been documented to be suitable for use in dietary toxicity tests with fish (Mount and others, 2006). Previous studies at the U.S. Geological Survey Columbia Environmental Research Center (CERC) have demonstrated that oligochaetes are a suitable diet for rearing juvenile pupfish through the onset of reproduction (Besser and others, 2004). Commercially produced selenized yeast, which contains Se predominantly (about 67 percent) as SeMet, was used to dose oligochaete diets with a range of Se concentrations suitable for dietary toxicity studies with pupfish. The objectives of Task 1 were: (1) determine the feasibility of dosing live oligochaetes by feeding with Se-dosed yeast; (2) optimize conditions for producing Se-dosed oligochaetes with consistent Se concentrations; and (3) characterize Se speciation in Se-dosed oligochaetes.

Task 2 characterized Se bioaccumulation and toxicity in juvenile and adult pupfish. This task characterized Se bioaccumulation, survival, and growth of pupfish during a 150-day F0 exposure (juvenile-adult), started with naïve F0 juveniles from a laboratory culture; and a 79-day F1 exposure (embryolarva-juvenile), started with eggs produced by Se-exposed F0 parents (table 2). The objectives of Task 2 were: (1) characterize Se bioaccumulation by pupfish throughout the life-cycle exposure, including whole-body and egg Se concentrations; (2) produce maternally Se-dosed embryos for the F1 exposure; and (3) evaluate effects of Se on survival and growth of juvenile and adult pupfish.

Task 3 characterized toxic effects of Se on reproduction and early life-stages of pupfish. Adult pupfish from the F0 exposure were used to evaluate the effect of long-term Se exposure on reproductive output of Se-dosed adults and on the hatching, development, and survival of F1 offspring following parental Se exposure (table 2). The objectives of Task 3 were: (1) evaluate the relative sensitivity of reproduction and early life-stage endpoints to Se toxicity; and (2) relate toxicity endpoints to tissue Se concentrations in parental (whole-body) tissues and in egg tissues.

The results of this study and concurrent field studies by Saiki and others $(2010,2011 \mathrm{a})$ provide a basis for a site-specific assessment of risks of Se toxicity to pupfish populations in the Imperial Valley.

\section{Methods}

\section{Task 1-Oligochaete Selenium Dosing}

\section{General Test Conditions}

Oligochaetes (Lumbriculus variegatus) were obtained from laboratory cultures. Selenium exposures were conducted in a flow-through exposure system comparable to that recommended by U.S. Environmental Protection Agency (U.S. Environmental Protection Agency, 2000) for sediment bioaccumulation tests. Small exposure chambers were 300 -milliliter $(\mathrm{mL})$ 
Table 2. Exposure groups, endpoints, and sampling schedule for a life-cycle selenium toxicity test with desert pupfish.

[Colors indicate different pupfish exposure groups (gray, no further exposure). Numbers in parentheses indicate sampling dates or frequency of sampling (weekly if no frequency is indicated). F0, first generation (parents); Se, selenium bioaccumulation; F1, second generation (offspring)]

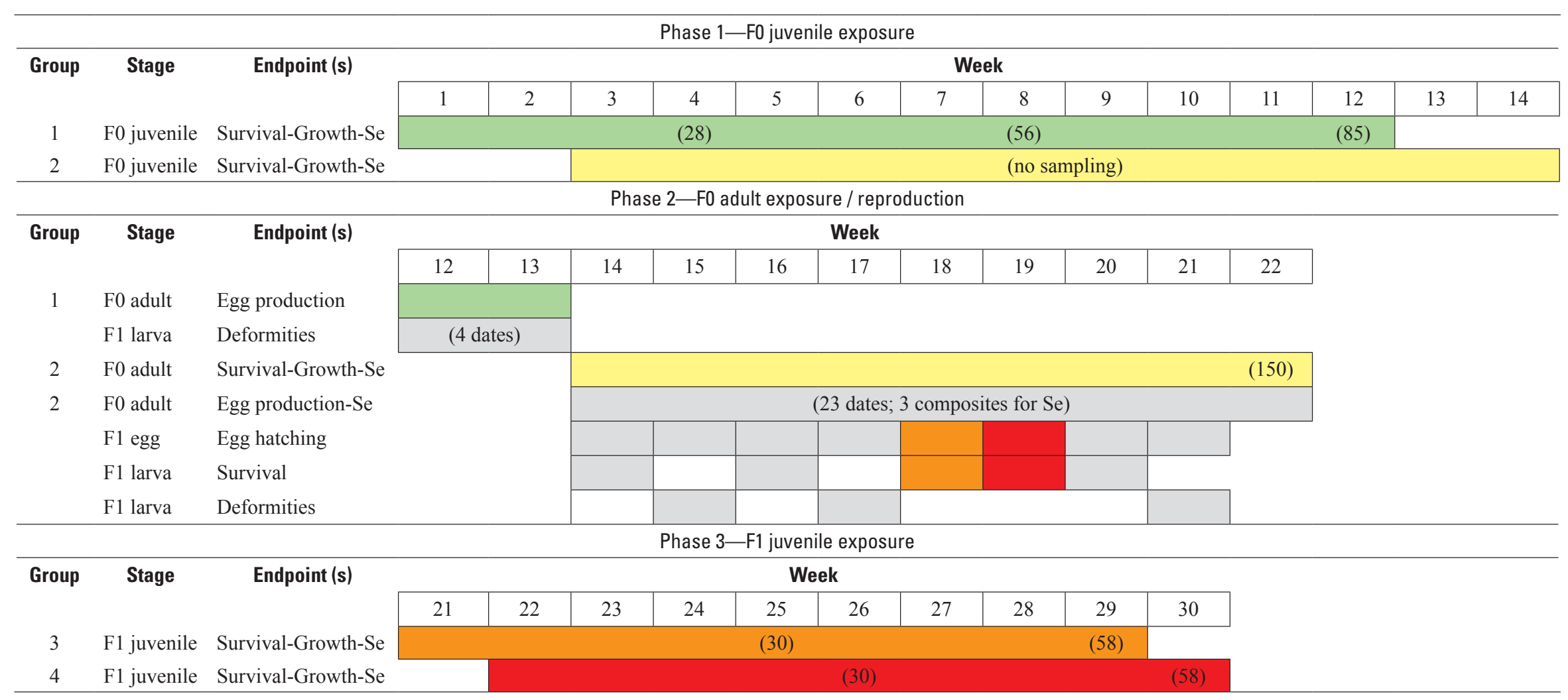


beakers containing $200-250 \mathrm{~mL}$ of water and $5 \mathrm{~mL}$ of clean sand. Large exposure chambers were 7-liter (L) glass aquaria containing $6 \mathrm{~L}$ water and $50 \mathrm{~mL}$ sand. Well water (hardness 280 milligrams per liter $[\mathrm{mg} / \mathrm{L}]$ as calcium carbonate) was added to the exposure chambers at a rate of about 10 volume additions per day (volume/day) using a proportional diluter. Water additions were increased as needed to maintain adequate dissolved oxygen levels in the chambers. Oligochaete feeding studies were conducted in water baths maintained at 23 degrees Celsius $\left({ }^{\circ} \mathrm{C}\right)$ with wide-spectrum fluorescent light (16 hours light: 8 hours dark). Oligochaetes were fed diets containing a range of Se concentrations that were prepared by mixing various proportions of selenized yeast and nutritional yeast. Selenized yeast (Selenosource AF 600; Diamond V Mills, Cedar Rapids, Iowa) had a mean Se concentration of $826 \mu \mathrm{g} / \mathrm{g}$ (expressed on a dry weight basis). Nutritional yeast (control yeast; Red Star ${ }^{\mathrm{TM}}$, Lesaffre Yeast Corporation, Milwaukee, Wisconsin) had a mean Se concentration of 0.27 $\mu \mathrm{g} / \mathrm{g}$. Endpoints for oligochaete feeding studies were oligochaete biomass and Se bioaccumulation. Oligochaete samples were rinsed and blotted with paper tissues in plastic weigh boats before determination of wet biomass, then transferred to tared aluminum weigh boats and dried $\left(24\right.$ hours at $\left.90^{\circ} \mathrm{C}\right)$ before determination of dry biomass and analysis of total Se. Water quality of exposure waters was monitored daily (temperature), weekly (dissolved oxygen), and biweekly (salinity, $\mathrm{pH}$, alkalinity, hardness, and ammonia).

\section{Range-Finding Study}

This study was conducted in small exposure chambers with four different starting masses of oligochaetes: 0.5 grams (g), $1 \mathrm{~g}, 2 \mathrm{~g}$, and $4 \mathrm{~g}$ blotted wet weight per chamber. Diets consisted of three yeast formulations (100 percent control yeast, 100 percent selenized yeast, and a 1:1 mixture of these components). Feeding suspensions for each diet were prepared daily ( $0.5 \mathrm{~g}$ yeast in $100 \mathrm{~mL}$ well water) and added to each beaker [ $5 \mathrm{~mL}$ or 25 milligrams ( $\mathrm{mg}$ ) per beaker per day] to produce daily rations ranging from 0.6 percent to 5 percent. Oligochaete rations are expressed as dry weight of yeast/ starting wet weight of oligochaetes. There were four replicate beakers per treatment combination. Final dry biomass of oligochaetes in each chamber was used to optimize rations for Se bioaccumulation and to evaluate possible toxic effects of selenized yeast on oligochaete biomass.

\section{Bioaccumulation Kinetics Study}

Oligochaetes were added to the small exposure chambers at two stocking densities ( $1 \mathrm{~g}$ and $2 \mathrm{~g}$ wet weight per chamber) and each chamber was fed $25 \mathrm{mg}$ dry weight of yeast daily, producing two daily rations: low $=1.25$ percent; high $=2.5$ percent. Diets consisted of a control (100 percent nutritional yeast) and three Se treatments with different percentages of selenized yeast: 6.3 percent, 25 percent, and 100 percent.
Measured Se concentrations in these dietary treatments were as follows: Control $=0.27 \mu \mathrm{g} / \mathrm{g}$, Low-Se $=53 \mu \mathrm{g} / \mathrm{g}$, Medium$\mathrm{Se}=205 \mu \mathrm{g} / \mathrm{g}$, and High-Se=826 $\mu \mathrm{g} / \mathrm{g}$. Two pre-exposure oligochaete samples were collected on day 0 , and two samples of oligochaetes from each treatment group were sampled on days $3,7,14,21$, and 28 for determination of oligochaete biomass and total Se concentrations.

\section{Dosing Regime Study}

Oligochaetes were dosed in (1) short-term exposures in small exposure chambers $(1 \mathrm{~g}$ oligochaetes and $150 \mathrm{~mL}$ water per beaker); and (2) long-term exposures in large exposure chambers ( $40 \mathrm{~g}$ oligochaetes and $6 \mathrm{~L}$ water per aquarium). Short-term and long-term dosing studies were conducted concurrently. In both small and large exposure chambers, the initial oligochaete density was $6.7 \mathrm{~g}$ (wet weight) per liter of water. In short-term exposures, the contents of two chambers per treatment were collected after three 7-day exposure intervals (days $0-7,7-14$, and 14-21). In long-term-exposures, duplicate $1.0 \mathrm{~g}$ subsamples were collected from the long-term exposure chambers on days 28,35 , and 42 . Oligochaetes in the short-term exposures were fed the high daily ration ( 2.5 percent) of Se-dosed yeast from Low-Se (6.25 percent selenized yeast), Medium-Se (25 percent), and High-Se (100 percent) treatments. Oligochaetes in the long-term exposure were fed the low daily ration (1.25 percent) of Se-dosed yeast at Very Low-Se (1.56 percent selenized yeast), Low-Se, and MediumSe treatments.

\section{Task 2-Selenium Bioaccumulation and Toxicity in Juvenile and Adult Pupfish}

\section{Pupfish Culture}

A pupfish culture was established at CERC in 2002 with 10 males and 28 females collected from Oasis Springs, California. Spawning pupfish were stocked in $40-\mathrm{L}$ aquaria at sex ratios of 3 males to 6 females. Aquaria received well water adjusted to 5 parts per thousand salinity (Instant Ocean), with an automatic timer to control water flow to provide one complete exchange daily. Pupfish were fed brine shrimp (Artemia sp.) nauplii and a flaked diet and foam biofilters were used in each aquarium to control ammonia. Aquaria were maintained at $25^{\circ} \mathrm{C}$ with a lighting cycle of 16 hours light: 8 hours dark. Spawning substrates were constructed from nylon scouring pads. Egg production was monitored daily and known-age juveniles from this culture were used to stock toxicity tests.

\section{Preparation of Selenium-Dosed Diets}

Pupfish were fed Se-dosed oligochaetes to produce the desired range of dietary Se concentrations, based on results of Task 1. Exposure conditions for pupfish are presented in appendix A. Diets for the five Se treatments were prepared by 
mixing control yeast and selenized yeast in a 50-percent dilution series, with a maximum nominal concentration of $100 \mu \mathrm{g}$ $\mathrm{Se} / \mathrm{g}$ (dry weight; 16 percent selenized yeast by weight).

Measured Se concentration in control yeast was $0.27 \mu \mathrm{g} \mathrm{Se} / \mathrm{g}$ and measured concentrations in the five Se treatments ranged from 6 to $98 \mu \mathrm{g} \mathrm{Se} / \mathrm{g}$. Se-dosed oligochaetes were prepared in a series of overlapping batches at each of the six exposure concentrations. Batches of oligochaetes (55 g wet weight per batch) were stocked into 7-L chambers containing $6 \mathrm{~L}$ of water and $50 \mathrm{~g}$ clean sand. Chambers received automated additions of clean well water ( 1 volume/day) and oligochaetes were fed $625 \mathrm{mg}$ of yeast daily (ration=1.25 percent) for a minimum of 28 days before they were sampled and fed to pupfish during a subsequent 7- to 14-day period. Daily portions of oligochaetes for each treatment were weighed to a target weight, based on the current size of the pupfish (adjusted weekly), and each daily portion was divided equally among replicate chambers.

\section{Pupfish Selenium Exposures}

Pupfish were exposed simultaneously to waterborne and dietary Se at six exposure levels (controls and five Se treatments) in a three-phase life-cycle exposure: Phase 1, naïve F0 juvenile exposure (85 days); Phase 2, F0 adult exposure (65 days) using pupfish exposed in the Phase 1; and Phase 3, F1 embryo-larva-juvenile exposure (79 days), using offspring from Phase 2 (table 2). Exposure conditions for pupfish are summarized in appendix B. All exposures were conducted at $25^{\circ} \mathrm{C}$ in well water augmented with salts (Instant Ocean) to a salinity of 5 parts per thousand. Both aqueous Se and dietary Se were delivered as five Se treatment levels in 50-percent dilution series, with target maximum Se concentrations of $48 \mu \mathrm{g} / \mathrm{L}$ in water and $50 \mu \mathrm{g} / \mathrm{g}$ (dry weight) in diet, plus a control. Measured Se concentrations in water and diets are summarized in table 3. Selenium stock solutions containing 85 percent of Se as sodium selenate and 15 percent of Se as sodium selenite (Sigma-Aldrich, St. Louis, Missouri) were prepared in de-ionized water and this mixture was delivered to 7-L exposure chambers containing $6 \mathrm{~L}$ of water by proportional diluters at a rate of 2 volumes/day. Feeding rations for juvenile pupfish were intended to approach satiation, as indicated by minimal food residue remaining in exposure chambers 4 hours after daily food additions. Rations were adjusted periodically based on increases in fish weights and observations of uneaten food. Pupfish rations averaged about 30 percent (wet weights) for juveniles and 25 percent for adults.

Phase-1 (F0) Se exposures were started with naïve juvenile pupfish at about 5 weeks post-hatch. Pupfish for the Phase-1 exposure were stocked in two separate exposure groups started several weeks apart, with each group consisting of 8 replicates (of 10 fish each) per treatment. Survival of pupfish was monitored daily. For the first F0 group, pupfish in four replicate groups per treatment were sampled after 28 days for determinations of growth (average wet weight) and whole-body Se concentrations. Five fish in the remaining four replicates were sampled on day 56 and surviving fish in these replicates were sampled on day 85 (table 2). For day-56 and day-85 samples, wet weights were determined for individual fish and one composite sample per replicate was frozen for whole-body Se analysis. Remaining fish from the first group were used for a preliminary reproduction study (described below under "Pupfish Reproduction"). Pupfish from the second group experienced the same Se exposure regime as the first group, except no replicates were sampled and all surviving fish were reared to reproductive maturity (12 weeks) for use in the main reproduction study (Phase-2 exposure; table 2), which is described below under "Pupfish Reproduction".

The Phase-3 (F1) exposure was started with two exposure groups of F1 larvae, hatched from eggs collected 1 week apart during the Phase-2 adult exposure (table 2). Of the eight replicates per treatment in the Phase-3 exposure, four replicates were started from each of the two F1 groups. At 14 days post-fertilization (dpf), about 7 days post-hatch, F1 larvae were transferred to static (1-L) exposure chambers with fresh Se solutions and fed uncontaminated brine shrimp nauplii and chopped, Se-dosed oligochaetes. Larval chambers were not aerated and dissolved oxygen was not monitored. At $21 \mathrm{dpf}$, F1 pupfish were transferred to 7-L exposure chambers in the Se diluter system and were fed Se-dosed oligochaetes-initially chopped (for about 2 weeks) and later whole. Survival of F1 juveniles was recorded after 30 and 58 days in the diluter exposure (table 2), with four replicates (two from each exposure group) sacrificed for measurement of wet weight and whole-body Se bioaccumulation on each sampling date.

Water samples were collected monthly from randomly selected replicates in each treatment during the pupfish exposures and frozen for analysis of total Se. Samples of oligochaete diets from each treatment were collected weekly and frozen to prepare composite samples for analysis of total Se, SeMet, and nutritional parameters. Endpoints for juvenile and adult pupfish exposures were survival, growth (weight), and whole-body Se bioaccumulation, which were determined after days $28,56,85$, and 150 of the F0 exposure (Phases 1 and 2) and after days 30 and 58 of the F1 exposure (Phase 3).

\section{Task 3-Effects of Selenium on Pupfish Reproduction}

\section{Pupfish Reproduction}

The reproduction study consisted of two parts. A preliminary reproduction study was conducted with adults from the first exposure group of F0 pupfish after 85 days of Se exposure. These fish were divided into two spawning groups and eggs were collected on four dates during a 9-day period (table 2). The main purpose of the preliminary study was to confirm the reproductive maturity of the pupfish, but samples of larvae from this study were used for assessment of deformities (described under "Morphological Deformities"). The main reproduction study was started with adults 
Table 3. Total selenium (Se) and selenomethionine (SeMet) concentrations in water, oligochaete diets, and pupfish tissue during lifecycle Se exposures.

[Total Se in water, oligochaetes, and pupfish eggs are means of all samples. Pupfish Se concentrations are means of samples from days 85 and 150 of the F0 exposure and days 30 and 58 of the F1 exposure. SeMet was analyzed on day 56 of the F0 exposure (1 sample per treatment). na, not applicable; nd, not detected; nm, not measured; <, less than; F0, first generation (parents); F1, second generation (offspring)]

\begin{tabular}{|c|c|c|c|c|}
\hline Treatment & Target total Se & Measured total Se & $\begin{array}{c}\text { Measured SeMet } \\
\text { (as Se) }\end{array}$ & $\begin{array}{c}\text { SeMet fraction } \\
\text { (percent of total Se) }\end{array}$ \\
\hline \multicolumn{5}{|c|}{ Filtered water, micrograms per liter (10 samples per treatment) } \\
\hline $\mathrm{Se}-1$ & 3 & 3.4 & $\mathrm{~nm}$ & $\mathrm{~nm}$ \\
\hline $\mathrm{Se}-2$ & 6 & 6.2 & $\mathrm{~nm}$ & $\mathrm{~nm}$ \\
\hline $\mathrm{Se}-5$ & 48 & 53 & $\mathrm{~nm}$ & $\mathrm{~nm}$ \\
\hline \multicolumn{5}{|c|}{ Oligochaetes, micrograms per gram dry weight (6 samples per treatment) } \\
\hline Control & na & 1.6 & nd & $<3$ \\
\hline $\mathrm{Se}-1$ & 3.1 & 5.1 & 1.6 & 27 \\
\hline $\mathrm{Se}-5$ & 50 & 52 & 20 & 35 \\
\hline \multicolumn{5}{|c|}{ F0 pupfish, whole-body, micrograms per gram dry weight (8 samples per treatment) } \\
\hline Control & na & 0.75 & 0.5 & 52 \\
\hline $\mathrm{Se}-1$ & na & 2.5 & 2.6 & 69 \\
\hline $\mathrm{Se}-2$ & na & 3.4 & 2.8 & 62 \\
\hline $\mathrm{Se}-3$ & na & 6.7 & 5.2 & 71 \\
\hline $\mathrm{Se}-4$ & na & 12 & 10 & 69 \\
\hline $\mathrm{Se}-5$ & na & 24 & 16 & 72 \\
\hline \multicolumn{5}{|c|}{ Pupfish eggs, micrograms per gram dry weight (3 samples per treatment) } \\
\hline $\mathrm{Se}-5$ & na & 27 & $\mathrm{~nm}$ & $\mathrm{~nm}$ \\
\hline \multicolumn{5}{|c|}{ F1 pupfish, whole-body, micrograms per gram dry weight (8 samples per treatment) } \\
\hline Control & na & 1.2 & $\mathrm{~nm}$ & $\mathrm{~nm}$ \\
\hline $\mathrm{Se}-1$ & na & 3.4 & $\mathrm{~nm}$ & $\mathrm{~nm}$ \\
\hline $\mathrm{Se}-2$ & na & 3.7 & $\mathrm{~nm}$ & $\mathrm{~nm}$ \\
\hline $\mathrm{Se}-3$ & na & 6.7 & $\mathrm{~nm}$ & $\mathrm{~nm}$ \\
\hline $\mathrm{Se}-4$ & na & 12 & $\mathrm{~nm}$ & $\mathrm{~nm}$ \\
\hline $\mathrm{Se}-5$ & na & 31 & $\mathrm{~nm}$ & $\mathrm{~nm}$ \\
\hline
\end{tabular}


from the second F0 exposure (table 2). These fish were sorted into spawning groups (1 male and 3 females) in 7-L exposure chambers, with eight replicate spawning groups per $\mathrm{Se}$ treatment. One spawning substrate, consisting of a bundle of five strips (about 3 centimeters wide and 20 centimeters long) of white nylon scrubbing pad (Scotch-Brite; 3M Company, St. Paul, Minnesota), was suspended in each exposure chamber. Spawning activity was monitored by removing (and replacing) spawning substrates from each chamber three times a week (Monday-Wednesday-Friday). There were 23 egg collection dates during a 60-day period. Eggs from each replicate were removed and counted on each collection date. Eggs from eight Wednesday collections were transferred with test solutions to polystyrene hatching cups (six circular cells, 35 millimeter cell diameter; Corning Costar) and hatching success was determined during a 10-day period (with a modal hatch date of $7 \mathrm{dpf}$ ). Hatched larvae were transferred to glass petri dishes with fresh Se test solution. Survival of unfed F1 larvae from three sampling dates was monitored under static conditions to $21 \mathrm{dpf}$, just before the onset of starvation. Larvae from three sampling dates were collected at $14 \mathrm{dpf}$ for examination of morphological deformities. Larvae from two sampling dates were used to start the F1 Se exposure, as described above under "Pupfish Se exposures". Eggs from other collection dates were added to frozen composite samples for analysis of egg Se concentrations. Surviving adults were counted, sexed, weighed, and preserved in formalin after 65 days (day 150 of the F0 exposure).

\section{Morphological Deformities}

Larval pupfish (10-14 dpf) were examined for morphological deformities. Larvae were preserved in 10-percent neutral buffered formalin and preserved samples were rinsed briefly in well water before observations. A dissecting microscope at 20x to 30x magnification (Nikon SMZ 1500) was used to evaluate each larva for abnormal development. Larvae were examined for edema; delayed development; and skeletal, eye, craniofacial, and fin deformities (Holm and others, 2005; Lemly, 1993c; Muscatello and others, 2006). The number and severity of abnormalities in each sample were recorded and representative photographs of abnormalities were taken.

During the preliminary reproduction study, there were 1,351 larvae collected at $10 \mathrm{dpf}$, of which 1,069 larvae had their yolk sac fully absorbed. During the main reproduction study, larvae from eggs collected during weeks 2, 4, and 8 were preserved at $14 \mathrm{dpf}$, after the yolk sac was completely absorbed (table 2). The target sample size for samples from the main reproduction study was 30 eggs per replicate on each sampling date and the actual number of larvae examined ranged from 3 to 32 per sample for a total of 1,376 larvae. Samples of larvae from one group of controls (four replicates from eggs collected on day 28) were not examined because the sample vials were lost. Limited numbers of adult pupfish from the reproduction study ( 87 fish; day 150 of the F0 exposure) and F1 juvenile pupfish (90 fish; day 58 the F1 exposure) also were preserved and examined for deformities.

\section{Chemical Analysis}

\section{Selenium Analysis}

Samples of test water, yeast mixtures, oligochaete diets, and pupfish tissues were analyzed for total Se to document $\mathrm{Se}$ exposure during all phases of the life-cycle exposure (table 3 ). Methods used for total-Se analysis were reported by May and others (2009). Water samples were collected during pupfish exposures and analyzed by hydride-generation atomic absorption spectrophotometry after a combination wet/dry ash digestion. Total Se concentrations in samples of yeast, oligochaetes, and pupfish tissues (whole-body and egg samples) were analyzed after digestion with nitric acid and hydrogen peroxide using isotope-dilution with 99.96 percent-pure ${ }^{77} \mathrm{Se}$ and ICPMS detection (Wan, 2007). Selected samples of oligochaetes and pupfish were extracted and analyzed by HPLC-ICP-MS to quantify SeMet concentrations (Wan, 2007). Freeze-dried tissues were processed by cryogenic pulverization to reduce the particle size of samples and increase extraction efficiencies. Extractions were performed at $120^{\circ} \mathrm{C}$ using $4 \mathrm{M}$ methylsulfonic acid fortified with an anti-oxidant modifier. All total Se and SeMet concentrations in tissue samples are reported on a dry weight basis, with moisture content determined for all tissue samples.

Total-Se and SeMet analyses were supported by analysis of certified reference materials, including a selenized yeast (SELM; National Research Council of Canada), which was the only known reference tissue certified for SeMet content. Measured concentrations of total Se in eight different certified tissue reference materials, including fish liver and muscle, oyster, lobster, bovine liver, and selenized yeast, were within the certified ranges except the lobster tissue, for which the mean measured value was 1 percent less than the lower limit of the certified range. Average recoveries for measurement of total Se spiked as SeMet before and after digestion of pupfish tissues were 95 percent and 96 percent, respectively. The relative standard deviation for total Se determinations in triplicate samples of whole pupfish tissue (from treatment $\mathrm{Se}-3$ ) was 1.9 percent. The relative standard deviation of triplicate analyses of a single tissue digestate was 0.7 percent.

Mean recoveries of SeMet spiked into oligochaete samples before and after extraction were 97 percent and 96 percent, respectively. The recovery of SeMet spiked into a control pupfish sample was 94 percent. The relative standard deviation (RSD) between triplicate extraction and analysis for SeMet in a sample of oligochaete tissue was 1.74 percent. The relative percent difference in SeMet concentration between duplicate extraction and analysis of a whole pupfish sample was 2.5 percent. Measured SeMet concentrations in two samples of the certified yeast material, expressed as mean dry-weight Se concentration (with standard deviation in parentheses) for 
triplicate analyses, were $1,357 \mu \mathrm{g} / \mathrm{g}(29 \mu \mathrm{g} / \mathrm{g})$ and $1,165 \mu \mathrm{g} / \mathrm{g}$ $\pm 116 \mu \mathrm{g} / \mathrm{g}$, values that compared favorably (84-98 percent recovery) with the certified value of $1,381 \mu \mathrm{g} / \mathrm{g} \pm 63 \mu \mathrm{g} / \mathrm{g}$. The mean percent of total Se measured as SeMet in the certified reference yeast was 66.5 percent, in close agreement with the reported value of 67.1 percent. A similar SeMet content (61 percent of total Se) was determined in the Selenosource yeast that was used to dose the oligochaetes. The method detection limit was about $0.05 \mu \mathrm{g} \mathrm{Se} / \mathrm{g}$ for either total Se or SeMet.

\section{Nutritional Analysis}

Composite samples of oligochaete diets from each Se treatment were analyzed to document nutritional quality across treatments. Nutritional analyses (Eurofins Scientific, Memphis, Tennessee) included caloric content, proximate analysis (percent moisture, protein, lipid, carbohydrate, and ash), amino acids, and fatty acids. Oligochaete diets averaged 390 calories $/ 100 \mathrm{~g}$, with 57 percent protein, 23 percent carbohydrate, and 7.6 percent lipid by weight. These constituents and profiles of amino acids and fatty acids in oligochaete diets were nearly identical across controls and Se treatments (appendix C).

\section{Water Quality}

Water quality in pupfish exposure chambers was characterized in randomly selected replicates of each treatment throughout the study. Temperature was maintained at $25 \pm 1^{\circ} \mathrm{C}$. Standard methods (American Public Health Association and others, 2005) were used to monitor water-quality parameters. Salinity, dissolved oxygen (membrane electrode), total ammonia (ion-selective electrode), and $\mathrm{pH}$ (combination electrode) were measured biweekly; total alkalinity (potentiometric titration) and total hardness (colorimetric titration) were measured monthly. Overall means (and ranges) for these parameters during the pupfish life-cycle exposure were: salinity, 4.8 (4.3-5.4) parts per thousand; $\mathrm{pH}, 8.33$ (7.95-8.71); dissolved oxygen, $6.8(3.9-8.9) \mathrm{mg} / \mathrm{L}$; total ammonia, $0.20(0.06-2.9) \mathrm{mg} / \mathrm{L}$ as nitrogen; total alkalinity, $253(186-370) \mathrm{mg} / \mathrm{L}$ as calcium carbonate; and total hardness, $975(710-1,800) \mathrm{mg} / \mathrm{L}$ as calcium carbonate (appendix D).

\section{Statistical Analysis}

Bioaccumulation data for oligochaetes and pupfish were characterized by fitting first-order exponential uptake models using SigmaPlot software (version 11; Systat, Chicago, Illinois). Output of these models $\left(\mathrm{C}_{\max }=\right.$ maximum Se concentration, $\mu \mathrm{g} / \mathrm{g}$; and $\mathrm{k}_{\mathrm{d}}=$ depuration rate, day $\left.^{-1}\right)$ were used to estimate dietary bioaccumulation factors $\left(\mathrm{BAF}=\mathrm{C}_{\text {max }}\right.$ /dietary Se concentration) and half-times for equilibration $\left(\mathrm{t}_{1 / 2}=0.693 / \mathrm{k}_{\mathrm{d}}\right)$.

Pupfish toxicity data were analyzed using SAS software (version 9.2; SAS Institute, Cary, North Carolina). Toxicity data were tested for normality (Shapiro-Wilk test) and examined for homogeneity of variance using box plots. Based on these findings, some data were transformed to logarithms (bioaccumulation), square roots (egg counts), arcsin square root (frequency of deformities) or ranks (Conover and Iman, 1981) before analysis of variance (ANOVA). Most toxicity data were analyzed by one-way ANOVA (for differences among treatments) or two-way ANOVA (for differences between treatment and sampling dates), with differences between Se treatments and controls tested using one-tailed Dunnett's tests. Differences in Se bioaccumulation among sampling dates were compared with Tukey's test. Egg production data were analyzed by repeated-measures ANOVA, with differences between treatments and controls evaluated with a least-squares mean procedure. Statements of statistical significance refer to a probability of Type-I errors (p) of 5 percent or less.

\section{Results and Discussion}

\section{Selenium Bioaccumulation by Oligochaetes}

\section{Range-Finding Study}

Oligochaetes accumulated Se readily from the Se-dosed yeast diets (fig. 1A). Oligochaete Se concentrations increased in proportion to Se content of the diet, with maximum Se bioaccumulation for each Se treatment occurring at a starting biomass of $1 \mathrm{~g}$ oligochaetes $/ 300 \mathrm{~mL}$ of water (corresponding to a ration of 2.5 percent). Final oligochaete biomass was affected by yeast Se concentrations (fig. $1 B$ ). In controls, oligochaete biomass remained stable (at starting biomass of 2 to $4 \mathrm{~g}$ ) or increased (from starting biomass of 0.5 to $1 \mathrm{~g}$ ), reflecting differences in feeding ration. In Se-dosed yeast treatments, oligochaete biomass remained stable (at low starting biomass) or decreased. Results of this study indicated that intermediate oligochaete stocking densities $(1-2 \mathrm{~g} / 300 \mathrm{~mL})$ and feeding rations (1.25-2.5 percent per day) were most appropriate for preparation of Se-dosed oligochaete diets.

\section{Bioaccumulation Kinetics Study}

Selenium bioaccumulation by oligochaetes differed among treatments (three Se-dosed yeast diets and two rations) during 27-day exposures (fig. 2). Se concentrations in oligochaetes fed Low-Se $(53 \mu \mathrm{g} / \mathrm{g})$ and Medium-Se $(205 \mu \mathrm{g} / \mathrm{g})$ diets leveled off by day 27, but Se concentrations in oligochaetes fed the High-Se diet $(826 \mu \mathrm{g} / \mathrm{g})$ continued to increase throughout the study. In Low-Se and Medium-Se treatments, oligochaetes fed the high ration (fig. $2 B$ ) accumulated greater Se concentrations at comparable Se concentrations in yeast diets, but the shapes of bioaccumulation curves did not differ substantially between the two ration treatments. First-order models indicated similar uptake kinetics for oligochaetes in 

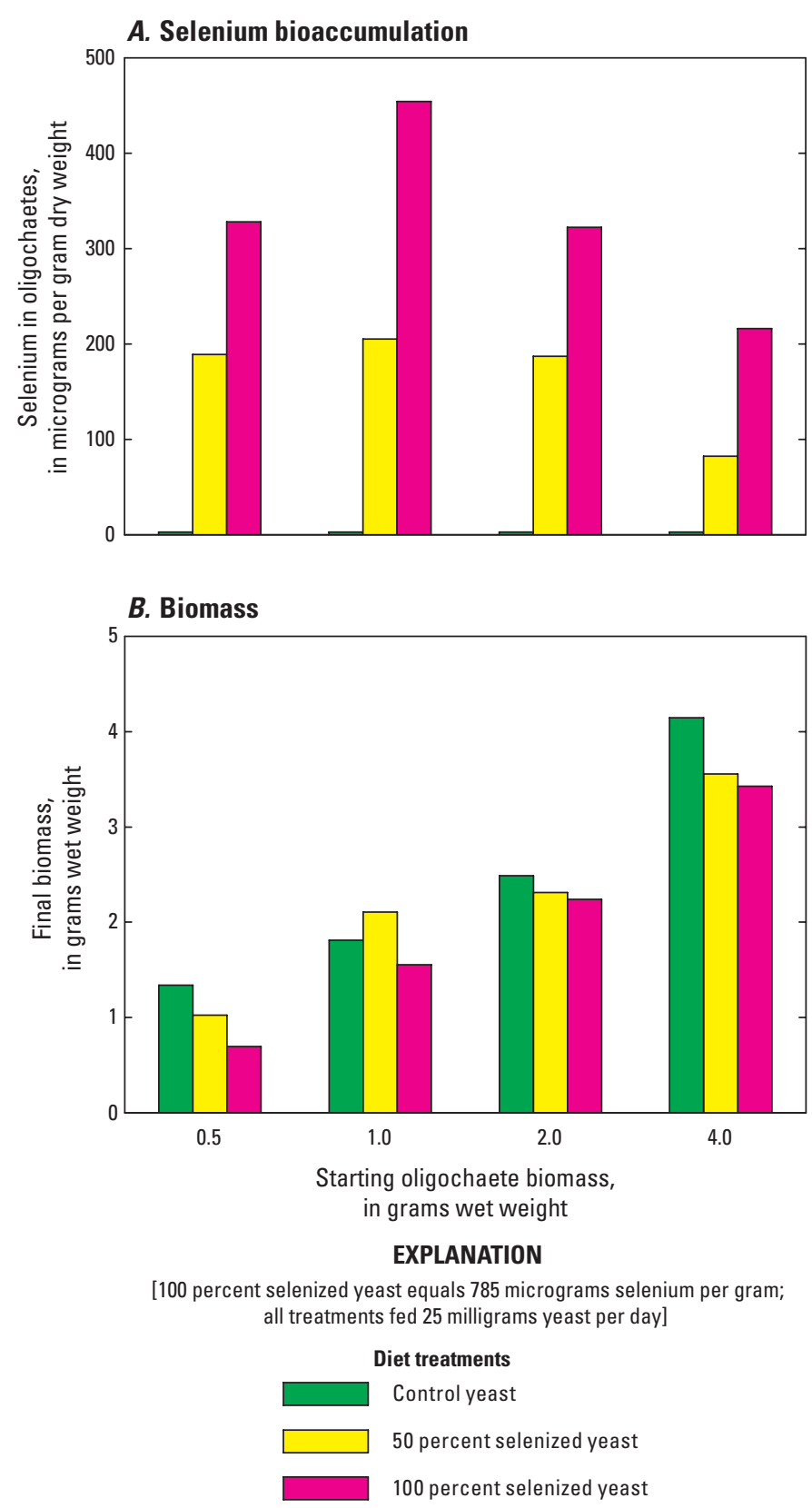

Figure 1. Effects of dietary selenium levels and feeding rations on oligochaetes in a 13-day range-finding test.

the Low-Se and Medium-Se treatments across the two rations (table 4). First-order uptake curves for these treatments had half-times between 5.1 and 5.8 days, indicating that oligochaetes in these treatments would reach more than 95 percent of equilibrium concentrations by 28 days. Modeled bioaccumulation factors (oligochaete Se/yeast Se) were 30 percent greater for the high-ration treatments.

Oligochaete biomass differed between yeast rations and among Se-dosed yeast treatments (fig. 3). In the Control, Low$\mathrm{Se}$, and Medium-Se treatments, oligochaete biomass remained stable throughout the 27-day period at the low ration and increased by about 50 percent in the high ration. Oligochaete biomass in the High-Se treatment decreased after day 14 at the low ration and after day 7 at the high ration. At the high ration, all oligochaetes were dead by day 27. Oligochaetes fed Sedosed yeast accumulated predictable tissue Se concentrations, and oligochaete biomass was not reduced at tissue Se concentrations of $140 \mu \mathrm{g} / \mathrm{g}$ or less (fig. 2), well above the upper target for dietary Se concentrations for toxicity tests with pupfish (52 $\mu \mathrm{g} \mathrm{Se} / \mathrm{g}$; table 3).

\section{Dosing Regime Study}

Reproducibility of oligochaete Se bioaccumulation from diets of Se-dosed yeast was compared between repeated shortterm exposures (7-day) and repeated sampling from long-term exposures (27- to 42-day). In two sets of exposures conducted in 2005 and 2006, Se concentrations in oligochaetes fed diets with the same Se concentrations in short-term exposures in small chambers with high rations averaged about one-half those in oligochaetes from long-term exposures in large chambers with low rations (fig. 4). Oligochaete Se concentrations from 2005 exposures (short- and long-term exposures) generally were slightly greater than those from 2006 , consistent with greater Se concentrations measured in yeast diets in 2005 . In 2006 exposures, Se concentrations in oligochaetes from long-term exposures increased by about one-third between days 28 and 42 .

Selenium concentrations in oligochaete tissues were more variable in short-term exposure than in long-term exposures (table 5). For short-term exposures, relative percent difference $(\mathrm{RPD}=$ range/mean) for duplicate samples from the same sampling date was 50 percent greater and relative standard deviation $(\mathrm{RSD}=$ standard deviation/mean) for multiple sample dates was twice as great as in the long-term exposures. These results indicated that repeated sampling from long-term exposures (28 days or longer) would provide diets with more consistent Se concentrations in the ranges needed for dietary toxicity studies with pupfish.

\section{Selenium Concentrations in Water, Diets, and Pupfish Tissues}

\section{Selenium Exposure Levels}

Total Se concentrations in exposure water and oligochaete diets were close to target concentrations (table 3). Filtered Se concentrations measured in selected samples ranged from 96 percent to 110 percent of total Se, indicating that little Se in unfiltered water samples was associated with particulates. Waterborne Se concentrations in controls were at or near detection limits. Mean Se concentrations in water and diets from treatments $\mathrm{Se}-1$ through $\mathrm{Se}-4$ approximated the range of site means for samples of filtered water $(1.5-22 \mu \mathrm{g} / \mathrm{L})$ and midge larvae $(3.5-25 \mu \mathrm{g} / \mathrm{g})$ for the seven Imperial Valley drains intensively monitored by Saiki and others (2010, 2011a). 
A. Low ration

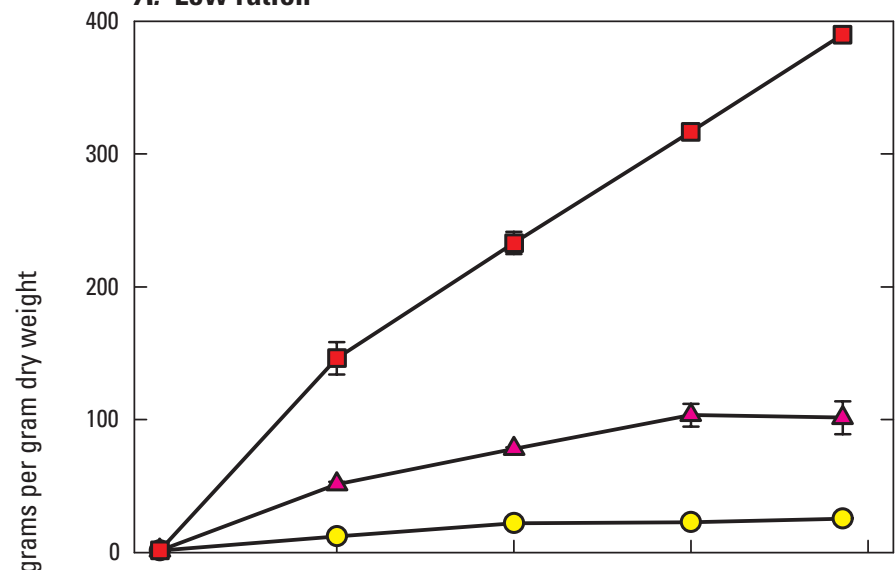

B. High ration

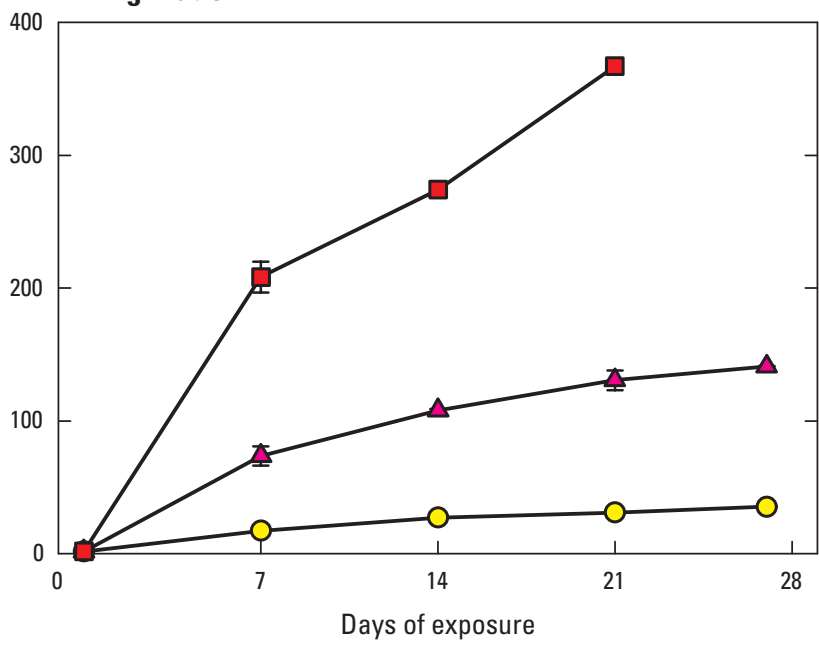

EXPLANATION

[Means of two analyses: low ration, 1.25 percent per day (dry weight/wet weight), high ration, 2.5 percent per day]

Dietary selenium treatments

-O- Low (52 micrograms per gram)

$\triangle$ Medium (205 micrograms per gram)

$\neg-$ High (826 micrograms per gram)

Figure 2. Selenium bioaccumulation by oligochaetes fed two rations of Se-dosed yeast diets in a 27-day bioaccumulation study.

\section{Pupfish Selenium Bioaccumulation}

Pupfish whole-body Se concentrations increased rapidly during the 150-day F0 Se exposures and did not change significantly between day 56 and day 150 in Se treatments Se-2 through Se-5 (fig. 5). In contrast, pupfish Se concentrations in the controls decreased from the starting concentration of $1.68 \mu \mathrm{g} / \mathrm{g}$, reaching a minimum of $0.71 \mu \mathrm{g} / \mathrm{g}$ on day 150 . The shape of uptake curves differed somewhat between Low- and High-Se treatments. In treatments $\mathrm{Se}-1$ and $\mathrm{Se}-2$, Se concentrations reached maxima at day 56 and decreased slightly thereafter; in treatments $\mathrm{Se}-3$ and $\mathrm{Se}-4$, Se concentrations

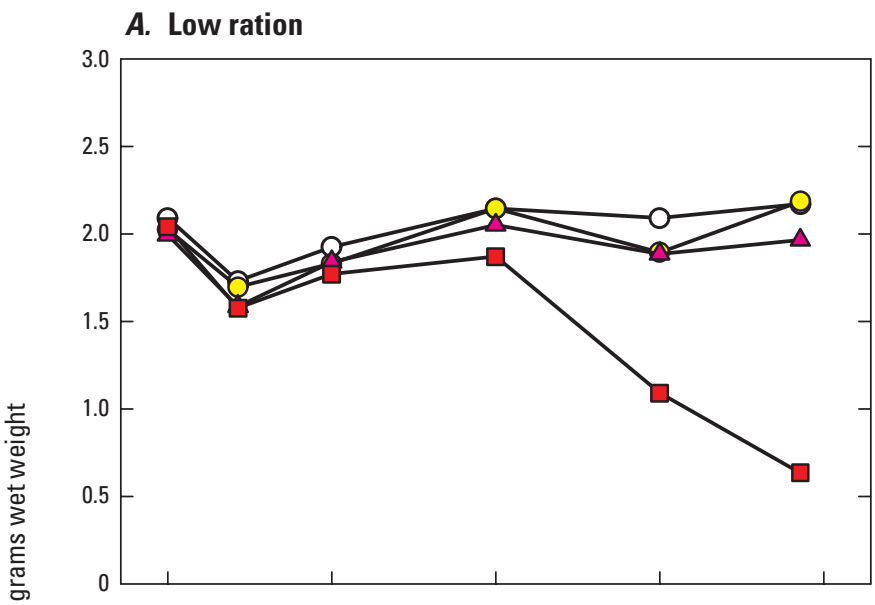

\section{B. High ration}

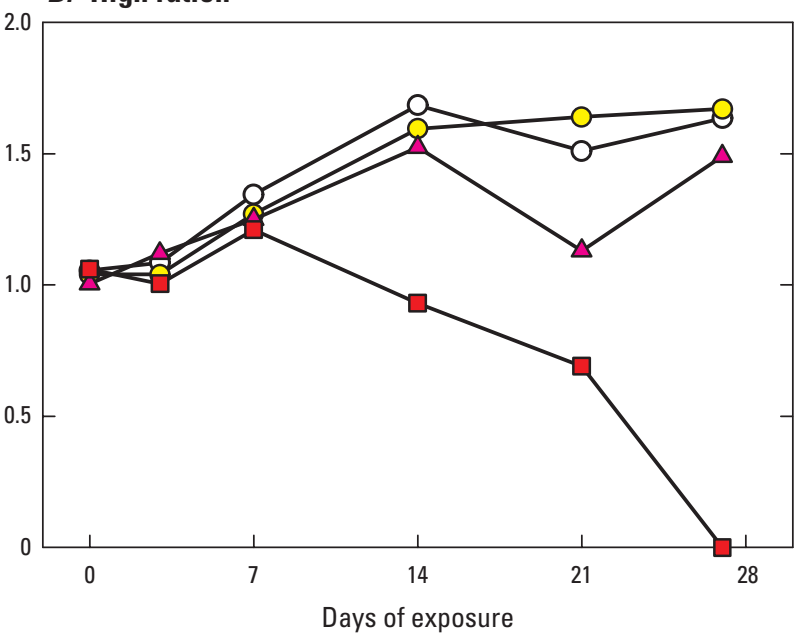

EXPLANATION

[Means of two analyses: low ration, 1.25 percent per day (dry weight/wet weight), high ration, 2.5 percent per day]

Dietary selenium treatments

-O- Control (0.27 micrograms per gram)

-O- Low (52 micrograms per gram)

$\triangle$ Medium (205 micrograms per gram)

$\square$ High (826 micrograms per gram)

Figure 3. Biomass of oligochaetes fed two rations of seleniumdosed yeast in a 27-day bioaccumulation study.

remained nearly constant from day 56 to day 150 ; and in the Se-5 treatment, Se concentrations increased gradually throughout the F0 exposure. However, mean whole-body Se concentrations in pupfish from each of the five Se treatments were nearly identical on days 85 and 150, the beginning and end dates of the reproduction study. Whole-body Se concentrations did not differ substantially between composite samples of male and female pupfish on day 150 (fig. 6).

Whole-body Se concentrations in pupfish from the Se treatments were fitted to exponential uptake models with halftimes ranging from 11 to 17 days (table 4). These models suggest that pupfish Se concentrations were more than 97 percent 
Table 4. First-order exponential models of selenium bioaccumulation by oligochaetes (from selenized yeast) and desert pupfish (from selenium-dosed oligochaetes).

[Se, selenium; Se-max, modeled maximum Se concentration in consumer; BAF, bioaccumulation factor (Se-max/diet Se); Half-time, time to reach 50 percent of Se-max]

\begin{tabular}{lccccc}
\hline Treatment & $\begin{array}{c}\text { Diet Se } \\
\text { (micrograms } \\
\text { per gram) }\end{array}$ & $\begin{array}{c}\text { Se-max } \\
\text { (micrograms } \\
\text { per gram) }\end{array}$ & BAF & $\begin{array}{c}\text { Depuration rate } \\
\text { (1/day) }\end{array}$ & Half-time \\
\hline Low ration & \multicolumn{7}{c}{ Oligochaetes (27-day study) } \\
Low ration & 53 & 30 & 0.57 & 0.136 & 5.1 \\
Low ration & 205 & 118 & .58 & .119 & 5.8 \\
High ration & 826 & 658 & .80 & .046 & 15.2 \\
High ration & 53 & 39 & .74 & .122 & 5.7 \\
High ration & 205 & 154 & .75 & .131 & 5.3 \\
\hline & 826 & 426 & .52 & .123 & 5.6 \\
\hline Se-1 & \multicolumn{2}{c}{ Pupfish (150-day study) } & & 12.4 \\
Se-2 & 5.1 & 1.16 & 0.23 & 0.056 & 12.2 \\
Se-3 & 7.3 & 1.93 & .26 & .057 & 10.7 \\
Se-4 & 14 & 5.04 & .36 & .065 & .042 \\
Se-5 & 24 & 10.9 & .45 & .046 & 16.5 \\
\hline
\end{tabular}

A. 7-day exposures

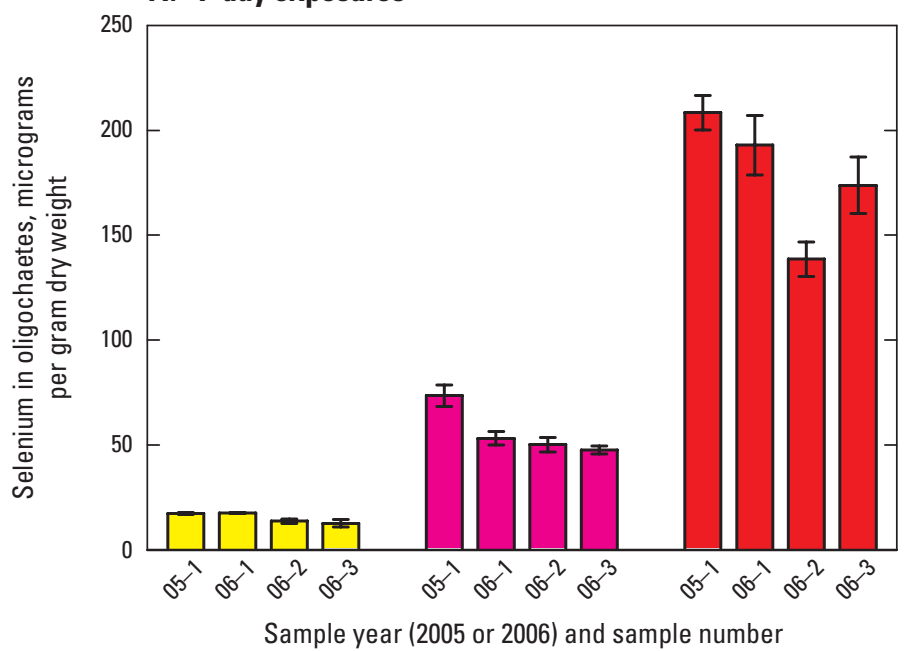

B. 42-day exposures

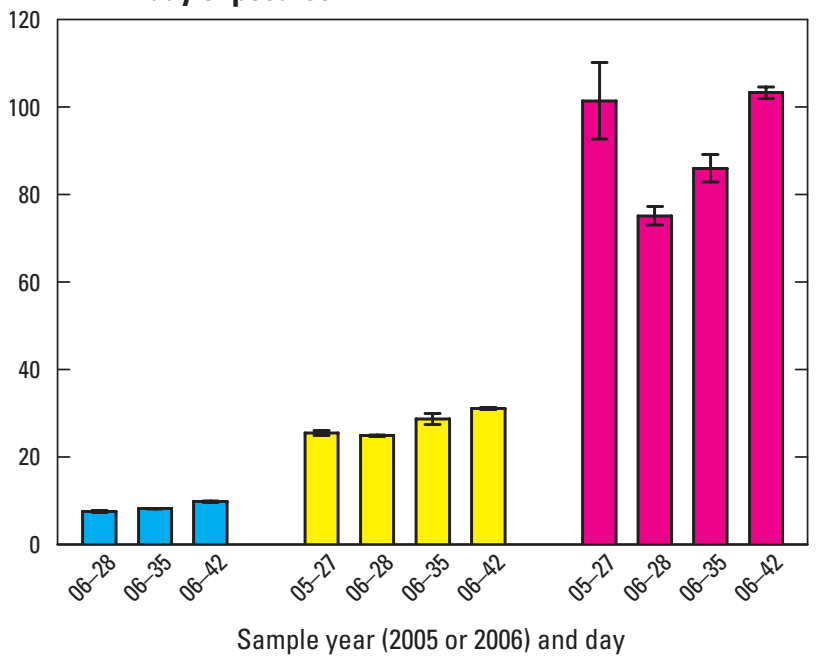

\section{EXPLANATION}

[Means and ranges of two samples]

Yeast selenium concentrations

Very low (15 micrograms per gram)

Low (53 micrograms per gram)

Medium (205 micrograms per gram)

High (826 micrograms per gram)

Figure 4. Selenium bioaccumulation by oligochaetes fed selenium-dosed yeast in two exposure regimes. 
Table 5. Variation of total selenium concentrations in oligochaetes under different exposure regimes.

[RPD, relative percent difference (difference divided by mean) based on two replicates; RSD, relative standard deviation (standard deviation divided by mean) based on three or four dates; $\mu \mathrm{g} / \mathrm{g}$, micrograms per gram]

\begin{tabular}{lcc}
\hline \multicolumn{1}{c}{ Selenium level } & $\begin{array}{c}\text { Within-date variation } \\
\text { (RPD, percent) }\end{array}$ & $\begin{array}{c}\text { Among-date variation } \\
\text { (RSD, percent) }\end{array}$ \\
\hline & Short exposure (7 days) & \\
\hline Low $(53 \mu \mathrm{g} / \mathrm{g})$ & 12.0 & 16.1 \\
Medium $(205 \mu \mathrm{g} / \mathrm{g})$ & 11.8 & 21.1 \\
High $(826 \mu \mathrm{g} / \mathrm{g})$ & 12.5 & 16.9 \\
Mean & 12.1 & 18.0 \\
\hline \multicolumn{3}{c}{ Long exposure (27-42 days) } \\
\hline Very Low $(15 \mu \mathrm{g} / \mathrm{g})$ & 3.8 & 13.8 \\
Low $(53 \mu \mathrm{g} / \mathrm{g})$ & 4.3 & 10.5 \\
Medium $(205 \mu \mathrm{g} / \mathrm{g})$ & 8.2 & 14.6 \\
Mean & 5.6 & 13.0 \\
\hline
\end{tabular}

of maxima by day 85 . Estimated bioaccumulation factors (fish Se concentration/diet Se concentration) for treatments $\mathrm{Se}-3$ through $\mathrm{Se}-5$ ranged from 0.36 to 0.42 . These half-times and bioaccumulation factors are similar to previous studies of dietary Se bioaccumulation (Besser and others, 1993). These results indicate that mean pupfish Se concentrations on days 85 and 150 (table 3) were suitable estimates of steadystate whole-body Se bioaccumulation during the 150-day F0 exposure.

Pupfish Se concentrations in the F1 exposure reflected parental Se transfer and subsequent dietary and aqueous exposure. Mean Se concentrations in eggs from all six treatments were consistently greater than whole-body Se concentration in F0 adults, although these differences were not statistically significant except in controls. This trend is consistent with reports of greater toxicity values for Se in eggs or ovaries of Se-exposed fish, compared to toxicity values based on wholebody Se concentrations (DeForest and others, 1999; Janz and others, 2010; Lemly, 1993a). DeForest and Adams (2011) estimated chronic toxicity thresholds for freshwater fishes of $17 \mu \mathrm{g} / \mathrm{g}$ for Se concentrations in eggs or ovaries and $8.1 \mu \mathrm{g} / \mathrm{g}$ for whole-body Se concentrations.

Selenium concentrations in pupfish eggs decreased during the course of the reproduction study (from the first to the third composite samples) in all treatment groups (fig. 6). Decreases in egg Se concentrations varied among treatments, with greatest decreases (44-51 percent) in treatments $\mathrm{Se}-2$, $\mathrm{Se}-3$, and $\mathrm{Se}-4$ and smallest decreases in treatments $\mathrm{Se}-1$ and Se-5 (12-15 percent). Whole-body Se concentrations were generally similar for $\mathrm{F} 0$ juveniles, F0 adults, and $\mathrm{F} 1$ juveniles, except for treatment $\mathrm{Se}-5$, where whole-body Se concentrations increased from $\mathrm{F} 0$ juveniles to $\mathrm{F} 0$ adults to $\mathrm{F} 1$ juveniles (fig. 5). Based on these results, pupfish Se exposure in the six treatments were characterized based on mean whole-body Se concentrations in F0 adults (days 85 and 150), mean Se concentrations in eggs (three composites per treatment), and mean whole-body Se concentrations in F1 juveniles (days 30 and 58; table 3 ).

The fraction of total-Se measured as SeMet differed among components of the laboratory Se-dosing system (table 3). Control oligochaetes did not contain detectable SeMet concentrations (less than $0.04 \mu \mathrm{g} / \mathrm{g}$, less than 3 percent of total Se). The SeMet fractions were consistent across the five Se treatments for both oligochaetes ( 27 to 36 percent) and F0 pupfish (62 to 72 percent). The increase in the SeMet fraction from oligochaetes to pupfish suggests that the SeMet in oligochaete diets was assimilated preferentially or retained preferentially (or both) by pupfish, compared to other Se species. These findings are consistent with a study (McIntyre and others, 2008) that reported bluegill (Lepomis macrochirus) fed diets spiked with 100 percent SeMet accumulated total Se concentrations 2.5 times greater than fish fed oligochaetes dosed with Se from selenized yeast.

The enrichment of SeMet content in the simplified laboratory food chain was more pronounced than trends observed in food-web components in pupfish habitats near the Salton Sea, where the SeMet content of diet items ranged from 6.7 percent (organic detritus) to 44 percent (midges) and the SeMet content of pupfish tissues was 52 percent (table 1). The greater SeMet content in our laboratory-dosed pupfish is consistent with their 100 percent invertebrate diet, whereas diets of field-collected pupfish included a large fraction of organic detritus (Saiki and others, 2011c).

\section{Toxicity of Selenium to Pupfish}

\section{Survival and Growth of Juveniles and Adults}

Survival and growth (in wet weight) of juvenile and adult pupfish showed few effects during the life-cycle Se exposure (table 6). In the F0 juvenile exposure (days 0-85), mean survival ranged from 98 percent to 100 percent across all treatments and controls. Survival of F0 adult pupfish during the reproductive study (days 85-150) ranged from 91 percent (in the controls and $\mathrm{Se}-4$ ) to 97 percent (in $\mathrm{Se}-5$ ). Mortalities during the reproduction study were all females and were presumably influenced by the aggressive behavior of the males. Survival of F1 juveniles was more variable among treatments, with lowest day-58 survival of 88 percent in the $\mathrm{Se}-5$ treatment, compared to 100 percent survival in the controls and Se-1 treatment. Survival did not differ significantly among treatments on any of the sampling dates, and none of the means for Se treatments were reduced significantly, relative to controls (rank ANOVA and Dunnett's test).

Pupfish grew rapidly in all treatments during the lifecycle exposure (table 6). Juvenile F0 pupfish roughly doubled in weight during the first two sampling intervals (days 28-56 and days 56-85) and weights of adults nearly doubled during 

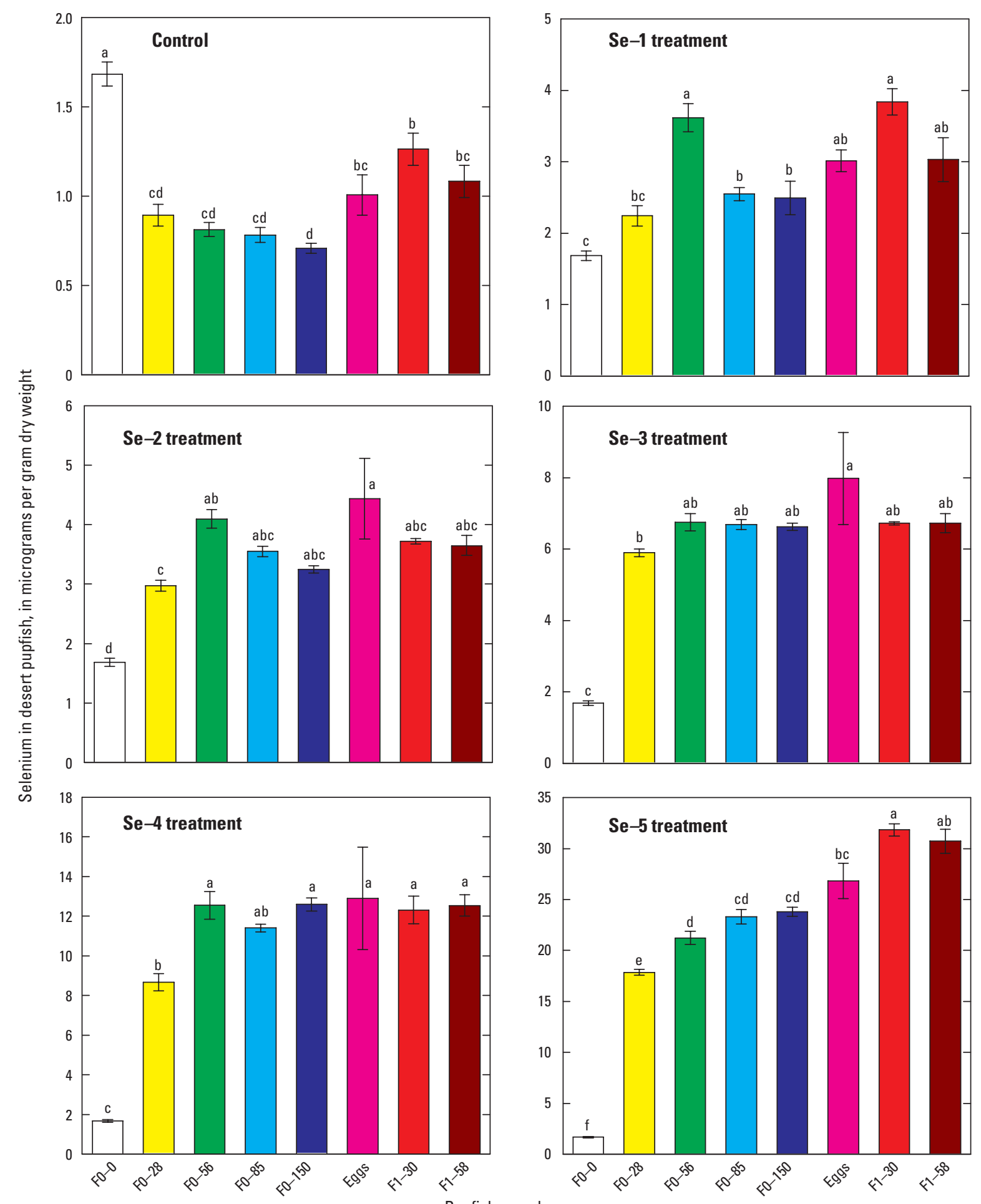

\section{EXPLANATION}

[Means and standard errors of three or four composite samples per group; within each treatment, means with the same letter are not significantly different (analysis of variance/Tukey's test); F0, parent generation; F1, offspring generation]

$$
\begin{array}{ll}
\begin{array}{l}
\text { Pupfish sample groups } \\
\text { Sample type }
\end{array} & \text { Days } \\
\text { F0 juveniles } & 0,28 \text {, and } 56 \\
\text { F0 adults } & 85 \text { and } 150 \\
\text { F1 eggs } & 85 \text { through } 150 \\
\text { F1 juveniles } & 30 \text { and } 58
\end{array}
$$

Figure 5. Selenium bioaccumulation in desert pupfish whole-body and egg samples during life-cycle selenium exposure: controls and five selenium levels (Se-1 through Se-5). 


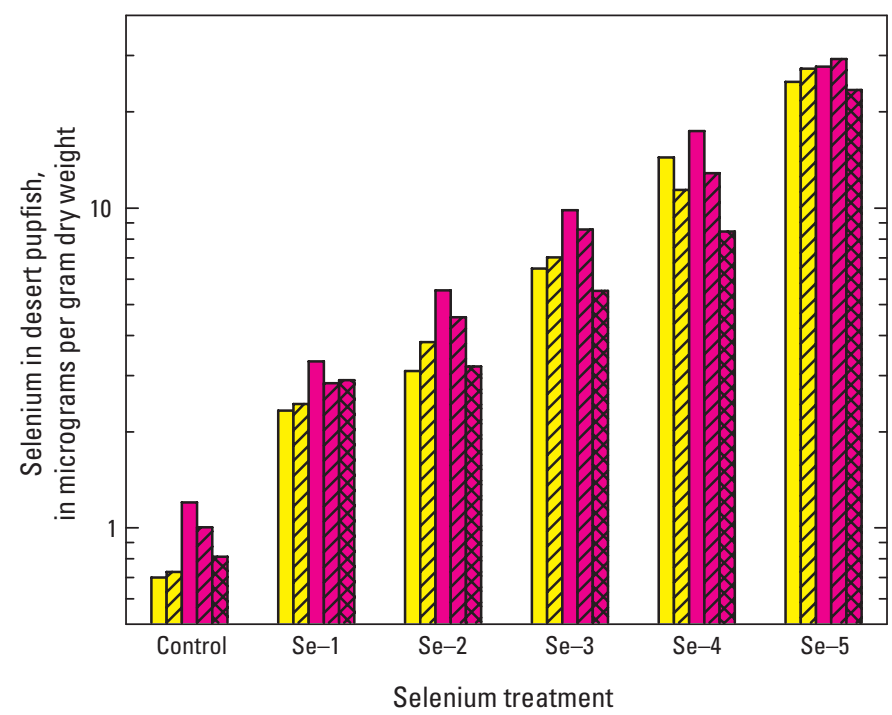

EXPLANATION

[Single composite whole-body samples of males and females collected on day 150; 3 composite samples of eggs collected between days 85 and 150]

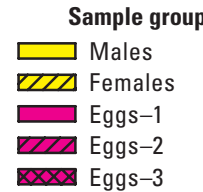

Figure 6. Selenium bioaccumulation in adult male and adult female desert pupfish and eggs from the main reproduction study.

the reproduction test (days 85-150). Pupfish in the F1 juvenile exposure were smaller at day 30 than the older F0 juveniles were at day 28 , but the $\mathrm{F} 1$ juveniles grew rapidly during the final 4-week exposure period, more than tripling in weight by day 58. The smaller size of the F1 pupfish at the first sampling date reflects their younger age at the start of the exposure ( $21 \mathrm{dpf}$ for F0 juveniles compared to about $42 \mathrm{dpf}$ for the F0 juveniles).

Differences in pupfish weight among Se treatments were small and transient (table 6). Treatment means did not differ significantly among the six treatments on any of the six sampling dates (rank ANOVA), but reductions in growth relative to controls were evident on some sampling dates, especially in treatment Se-5. Reductions in growth in Se-5 were greatest for F0 juveniles on day 56 (16 percent reduction; significant Dunnett's test) and F1 juveniles on day 30 (21 percent reduction). However, differences in weight among treatments decreased with time in F0 and F1 juvenile exposures. Mean weights for the Se-5 treatment in the F0 exposure were greater than controls by day 85 and mean weights for F1 juveniles from the $\mathrm{Se}-5$ treatment were nearly equal to controls by day 58. Mean weights of adults in the Se- 4 and $\mathrm{Se}-5$ treatments were 5-10 percent less than controls on day 150 (table 6).

\section{Egg Production}

Egg production in the main reproduction study varied widely among treatment groups and varied over time within treatment groups. Raw egg production data are available online in appendix E. Average daily egg production (means of 8 replicates per treatment) varied with time in all treatments (fig. $7 A$ ), with minimum daily egg production for individual treatments ranging from 5 to 16 eggs per replicate and maximum daily production ranging from 38 to 83 eggs per replicate. Egg production in the controls had the lowest variation among sampling dates, with a relative standard deviation of 33 percent compared to RSDs ranging from 48 percent to 64 percent for the five Se treatments. Egg production was relatively consistent among treatments for the first 2 weeks of the study, but varied more widely thereafter. Controls had the greatest cumulative egg production (855 eggs/replicate; fig. $7 B$ ), and cumulative egg production decreased with increasing Se exposure for treatments Se-1 through Se-4, (417 eggs/replicate). However, cumulative egg production in the $\mathrm{Se}-5$ treatment was greater (653 eggs/replicate) than three treatments with lower Se exposure.

In addition to variation with time and among treatments, egg production varied among replicate spawning groups. Eleven of 48 replicates did not have the full complement of three females during all or part of the study. Three replicates were stocked inadvertently with two females and two males because the second males did not show male secondary sex characteristics at the start of the reproduction study. These errors were not detected until mortality of the second male occurred, presumably because of aggression by the dominant male. Eight replicates lost females to mortality during the study. Losses of females by mortality were not replaced because almost all mortalities occurred during the second month of the study, when Se-exposed replacement fish were not available. By the end of the reproduction study, between one and three replicates in each Se treatment had fewer than three females, with one control replicate having only one surviving female. To examine the influence of differing numbers of females on variation in egg production, daily egg production was calculated both as eggs per replicate (fig. $8 A$ ) and as eggs per surviving female (fig. $8 B$ ). This comparison suggested that female mortalities led to increased egg production of surviving females, presumably reflecting reduced crowding and increased food availability. This compensatory response was most evident in the control replicate with one surviving female, which had egg production more than double that in any other replicate, when expressed as eggs per female.

Results of statistical analyses of egg production data (square root transformation) among treatments differed somewhat, depending on whether egg production was expressed on a per-replicate or per-female basis. Simple one-way ANOVAs of cumulative egg production did not indicate significant differences among treatments on either a per-replicate basis $(\mathrm{p}=0.34)$ or on a per-female basis $(\mathrm{p}=0.20)$. However, Dunnett's test indicated that treatment $\mathrm{Se}-4$ had significantly 
Table 6. Survival and growth of pupfish during a life-cycle selenium exposure.

[Treatment means and standard errors, with results of one-way ANOVA. Four replicates per treatment, except eight replicate spawning groups per treatment (F0 exposure, day 150). ANOVA, analysis of variance; p, probability of type-I error; F0, first generation (parents); Se, selenium; *, asterisk indicates mean significantly less than control (Dunnett's test); F1, second generation (offspring)]

\begin{tabular}{|c|c|c|c|c|c|c|}
\hline Treatment & $\begin{array}{l}\text { Survival, } \\
\text { mean } \\
\text { (percent) }\end{array}$ & $\begin{array}{c}\text { Survival, } \\
\text { standard error } \\
\text { (percent) }\end{array}$ & $\begin{array}{c}\text { Survival } \\
\text { ANOVA } \\
\text { (p) }\end{array}$ & $\begin{array}{c}\text { Growth, } \\
\text { mean } \\
\text { (milligrams } \\
\text { wet weight) }\end{array}$ & $\begin{array}{c}\text { Growth, } \\
\text { standard error } \\
\text { (milligrams } \\
\text { wet weight) }\end{array}$ & $\begin{array}{c}\text { Growth } \\
\text { ANOVA } \\
\text { (p) }\end{array}$ \\
\hline \multicolumn{7}{|c|}{ F0 exposure, day 28} \\
\hline Control & 100 & 0 & 0.446 & 213 & 3 & 0.379 \\
\hline $\mathrm{Se}-1$ & 100 & 0 & & 206 & 6 & \\
\hline $\mathrm{Se}-3$ & 100 & 0 & & 198 & 3 & \\
\hline $\mathrm{Se}-4$ & 100 & 0 & & 213 & 6 & \\
\hline $\mathrm{Se}-5$ & 98 & 3 & & 203 & 9 & \\
\hline \multicolumn{7}{|c|}{ F0 exposure, day 56} \\
\hline Control & 100 & 0 & 1.000 & 535 & 26 & 0.161 \\
\hline $\mathrm{Se}-4$ & 100 & 0 & & 509 & 27 & \\
\hline $\mathrm{Se}-5$ & 100 & 0 & & $447 *$ & 39 & \\
\hline \multicolumn{7}{|c|}{ F0 exposure, day 85} \\
\hline Control & 100 & 0 & 1.000 & 935 & 71 & 0.693 \\
\hline $\mathrm{Se}-1$ & 100 & 0 & & 998 & 70 & \\
\hline $\mathrm{Se}-2$ & 100 & 0 & & 941 & 68 & \\
\hline $\mathrm{Se}-3$ & 100 & 0 & & 934 & 54 & \\
\hline $\mathrm{Se}-4$ & 100 & 0 & & 914 & 87 & \\
\hline $\mathrm{Se}-5$ & 100 & 0 & & 1,053 & 46 & \\
\hline \multicolumn{7}{|c|}{ F0 exposure, day 150} \\
\hline \multicolumn{7}{|c|}{ F1 exposure, day 30} \\
\hline Control & 100 & 0 & 0.564 & 73 & 5 & 0.610 \\
\hline $\mathrm{Se}-1$ & 100 & 0 & & 73 & 11 & \\
\hline $\mathrm{Se}-2$ & 100 & 0 & & 76 & 7 & \\
\hline $\mathrm{Se}-3$ & 100 & 0 & & 78 & 11 & \\
\hline $\mathrm{Se}-4$ & 98 & 3 & & 77 & 10 & \\
\hline $\mathrm{Se}-5$ & 98 & 3 & & 58 & 7 & \\
\hline \multicolumn{7}{|c|}{ F1 exposure, day 58} \\
\hline Control & 100 & 0 & 0.228 & 260 & 7 & 0.689 \\
\hline $\mathrm{Se}-1$ & 100 & 0 & & 264 & 10 & \\
\hline $\mathrm{Se}-2$ & 93 & 8 & & 286 & 34 & \\
\hline $\mathrm{Se}-3$ & 90 & 4 & & 286 & 15 & \\
\hline $\mathrm{Se}-4$ & 95 & 3 & & 288 & 14 & \\
\hline $\mathrm{Se}-5$ & 88 & 8 & & 255 & 22 & \\
\hline
\end{tabular}


A. Egg production by sampling date

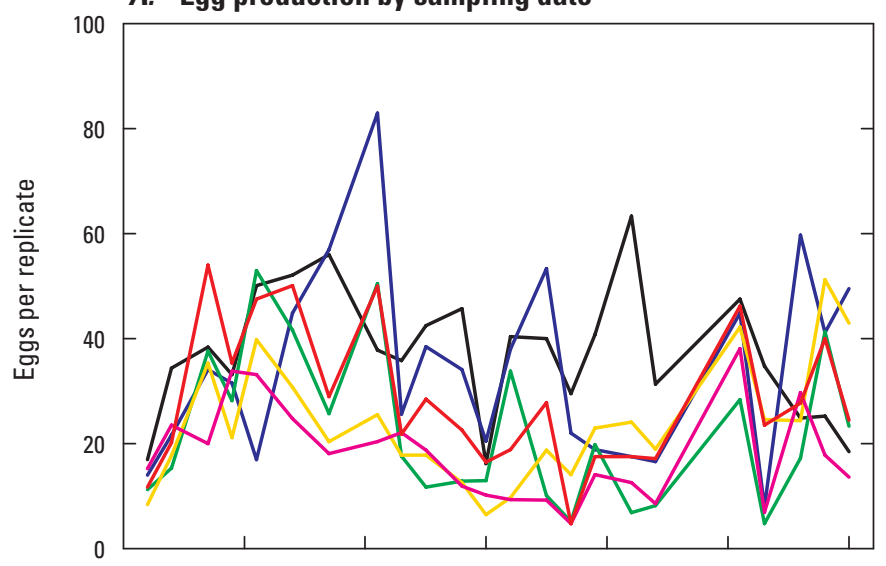

B. Cumulative egg production

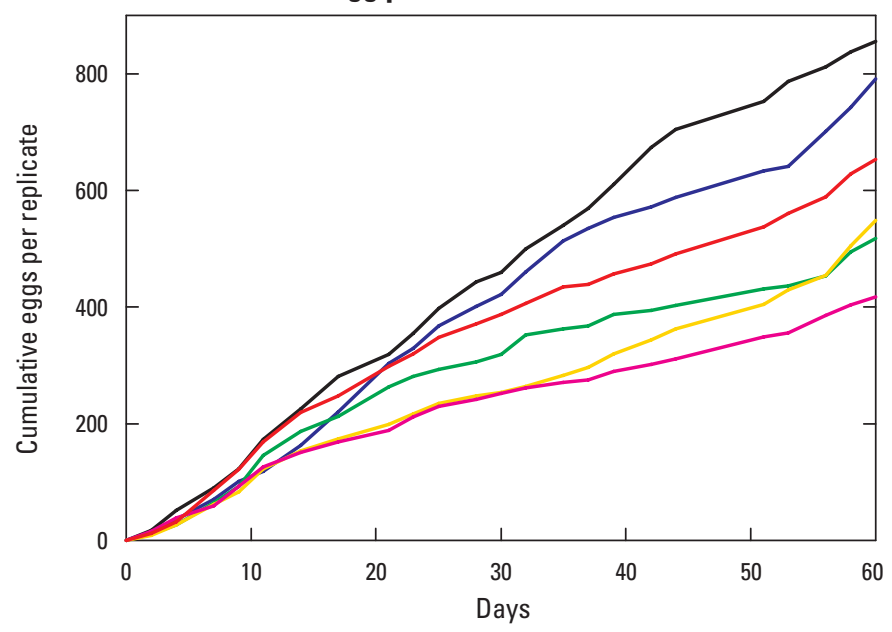

EXPLANATION

[Means of eight replicates per treatment]

Selenium treatments

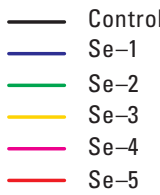

Figure 7. Egg production by desert pupfish during life-cycle selenium exposure.

reduced per-female egg production, compared to the controls. More detailed analyses of the egg production data were conducted using repeated measures ANOVA, which examined differences among treatments, differences among sampling dates, and treatment $X$ date interactions. Repeated measures ANOVA based on per-replicate and per-female egg production data produced similar results, with no significant overall differences among Se treatments, but significant differences among sampling dates and significant interactions of treatment and date (table 7). The significant treatment $X$ date interactions indicated that differences in egg production among treatments were not constant during the course of the study. These temporal trends were examined using comparisons of least-square

\section{A. Egg production per replicate}

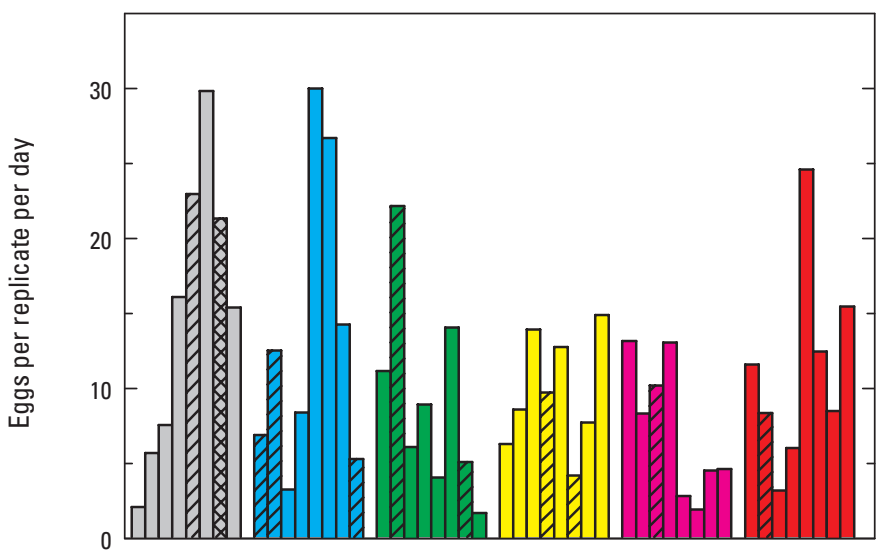

B. Egg production per female

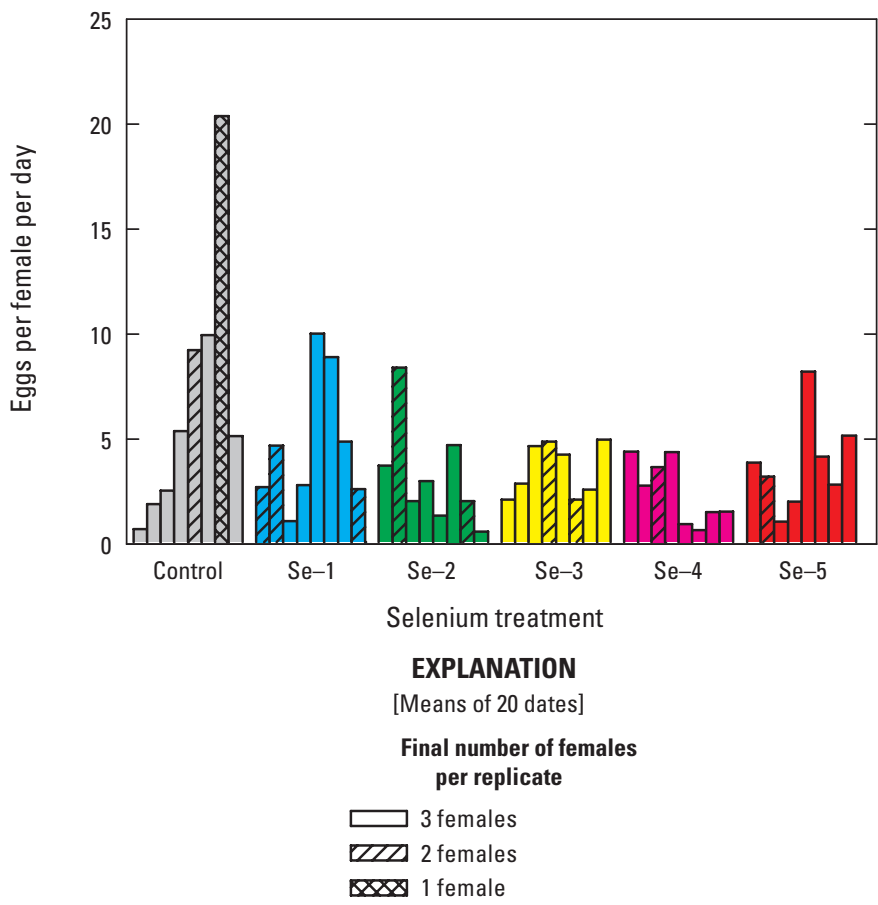

Figure 8. Variation in desert pupfish egg production among replicate spawning groups.

means, which allowed examination of the significance of differences between pairs of treatments on individual sampling dates. Least-squares mean comparisons between Se treatments and controls indicated that daily mean egg production was reduced significantly relative to controls in all Se treatments on multiple dates, but was not increased significantly relative to controls in any treatment on any date. For the eggs-perfemale analysis, significant reductions occurred on a minimum of 4 of 23 sampling dates (in treatments $\mathrm{Se}-1$ and $\mathrm{Se}-5$ ) and a maximum of 10 dates (in treatment $\mathrm{Se}-4$ ) (table 7). For the eggs-per-replicate analysis, the number of dates with significant reductions in egg production relative to controls followed similar trends among treatments, with significant differences 
Table 7. Summary of repeated-measures ANOVA and leastsquares means comparisons for effects of selenium on pupfish egg production.

[Comparison of analyses of data on daily egg production expressed as eggs per replicate or eggs per female. Data were transformed to square roots before analysis. ANOVA; analysis of variance; p-values, probability of type-I error; Se, selenium; <, less than]

\begin{tabular}{lcc}
\hline $\begin{array}{c}\text { ANOVA effect or } \\
\text { treatment }\end{array}$ & $\begin{array}{c}\text { Eggs per replicate } \\
\text { per day }\end{array}$ & $\begin{array}{c}\text { Eggs per female } \\
\text { per day }\end{array}$ \\
\hline \multicolumn{3}{c}{ Repeated measures ANOVA (p-values) } \\
\hline Se treatment & 0.257 & 0.14 \\
Date & $<.0001$ & $<.0001$ \\
Se X Date interaction & .0058 & .0037 \\
\hline \multicolumn{4}{c}{ Least-squares means comparisons } \\
(number of days treatment was less than controls) \\
Se-1 & 3 & 4 \\
Se-2 & 6 & 9 \\
Se-3 & 4 & 5 \\
Se-4 & 7 & 10 \\
Se-5 & 3 & 4 \\
\hline
\end{tabular}

occurring on three to seven dates per treatment group (table 7; fig. 9). Few significant differences in egg production occurred early in the reproduction study (only 4 before day 28), but the frequency of significant differences increased during the middle of the study ( 16 between days 28 and 44 ) before decreasing again at the end of the study ( 3 between days 44 and 60). Of the 18 daily treatment means that were greater than control means, 6 were in treatment Se-1, 9 occurred in the last week of the study and none was significantly greater than control means. These results suggest that egg production by pupfish was reduced by Se exposure, although these reductions were not constant throughout the study and the trend for reduced egg production with increasing Se exposure was partially reversed in the Se-5 treatment.

Egg production has not been reported as a sensitive response of freshwater fish to Se exposure. Laboratory or mesocosm studies of Se toxicity to fish that reported egg production data indicated either that numbers of spawns or egg productions were not reduced significantly or that these endpoints were no more sensitive than other endpoints (Coyle and others, 1991; Hermanutz and others, 1992; Ogle and Knight, 1989). Saiki and Ogle (1995) reported significant reductions of brood size of field-collected western mosquitofish (Gambusia affinis), but only at extremely high whole-body Se concentrations of $93-150 \mu \mathrm{g} / \mathrm{g}$. However, reduced egg production by other Cyprinidon pupfish has been reported as a sensitive sublethal response to a variety of environmental stressors, including temperature (Shrode and Gerking, 1977), salinity (Gerking and Lee, 1980), and acidity (Lee and Gerking, 1980). Reduced egg production by Se-dosed pupfish could reflect pathological effects of Se on egg development. Sorenson and Bauer (1984) and Sorensen (1988) reported ovarian abnormalities,

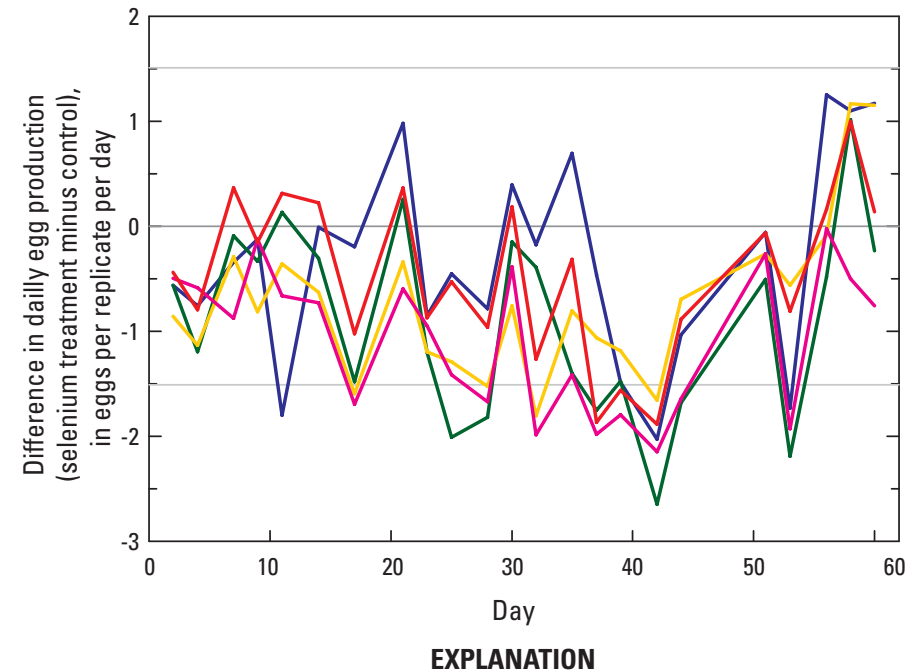

[Differences in least-square means of square root-transformed data; values outside area defined by gray lines are significantly different than control]

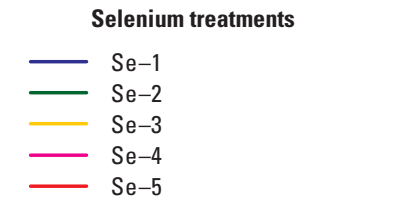

Figure 9. Differences in desert pupfish egg production between selenium treatments and controls by sampling date.

including reduced numbers of oocytes, atresia (malformed or reabsorbed ovarian follicles) and necrosis, in Se exposed sunfish (Lepomis spp.), which could contribute to reduced egg production. An apparent contradiction to the ovarian pathology hypothesis was the increased egg production in several Se treatments late in the study. These late increases could reflect a belated onset of full egg production in the maturing pupfish after delay induced by Se exposure or it could reflect changes in Se concentrations in developing ovaries. Whole-body Se concentrations in composite samples of adult pupfish did not change significantly during the reproductive period (fig. 5), but Se concentrations in eggs from all Se treatments decreased during this period (fig. 6). These changes do not simply reflect depletion of ovarian Se burdens resulting from egg production, because greatest decreases in egg Se concentrations occurred in treatments with lowest egg production (that is, reductions of 44-51 percent in treatments $\mathrm{Se}-2, \mathrm{Se}-3$, and $\mathrm{Se}-4)$. None of these hypotheses can fully explain the results from the Se-5 treatment, which had lesser reductions in egg production, relative to controls, despite having consistently greater $\mathrm{Se}$ concentrations in adults and eggs.

\section{Egg Hatching and Larval Survival}

Differences in egg production among Se treatments were not reflected by hatching success or survival of hatched larvae (fig. 10). Egg hatching and larval survival were generally consistent among Se treatments, with typical ranges of 88 percent 


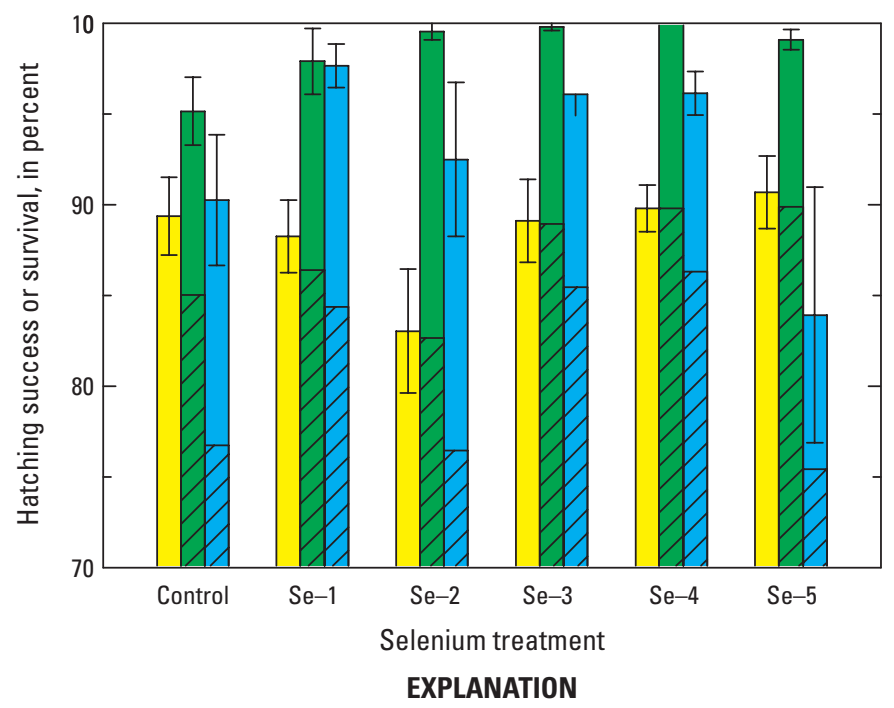

[Means and standard errors for 8 dates for hatching, 7 dates for survival at 14 days post-fertilization (dpf), and 5 dates for survival at $21 \mathrm{dpf}]$

\begin{tabular}{|c|c|}
\hline$\square$ & Egg hatching (7 dpf) \\
\hline & Larval survival (14 dpf) \\
\hline & Larval survival (21 dpf) \\
\hline ZZZ & Cumulative hatching and survival (14 dpf) \\
\hline ZZZ & Cumulative hatching and survival (21 dpf) \\
\hline & Standard error \\
\hline
\end{tabular}

Figure 10. Egg hatching and larval survival during the main reproduction study.

to 91 percent for egg hatching and 90 percent to 98 percent for larval survival (at $21 \mathrm{dpf}$ ). The only treatment means outside these ranges were hatching success of 83 percent in Se-2 and larval survival of 84 percent in Se-5. Cumulative survivorship from egg deposition through $21 \mathrm{dpf}$ was 81 percent in controls and ranged from 76 percent (in Se-5) to 86 percent in Se treatments.

Analysis of variance for effects of treatment, sampling date, and treatment $\mathrm{X}$ date interactions were not significant for egg hatching $(\mathrm{p}=0.08)$, but were significant for larval survival on day $14(\mathrm{p}=0.015)$ and day $21(\mathrm{p}=0.0004)$. Larval survival differed significantly among treatments after 14 days $(\mathrm{p}<0.0001)$ and 21 days $(\mathrm{p}=0.006)$, but none of the Se treatments had mean larval survival that was significantly less than controls (Dunnett's test). Mean survival at $21 \mathrm{dpf}$ also differed significantly among egg collection dates during the reproduction study, with significantly greater survival for eggs collected on day 42 than for eggs collected on days 2 and 14 . In samples from day 2 and day 14, survival at $21 \mathrm{dpf}$ averaged 77 percent in the Se-5 treatment, compared to 87 percent in controls and 97 percent in other Se treatments, but 21-dpf survival did not differ among treatments for eggs collected on day 42 (range: 97-100 percent).

\section{Morphological Deformities}

Several types of morphological abnormalities were observed in F1 pupfish larvae (fig. 11; table 8). The most common deformities (more than 80 percent of totals) were spinal deformities (lordosis and scoliosis), followed by eye and fin deformities (less than 10 percent of totals). Edema, delayed development, and craniofacial deformities were rarely observed ( $<2$ percent of total). Frequencies of different types of deformities were similar for larvae from the preliminary and main reproduction studies (table 8). These observations are consistent with other reports of Se toxicity to fish (Hermanutz and others, 1992; Holm and others, 2005; Lemly, 1993c) and with disruption of musculoskeletal development by Se toxicity (Teh and others, 2002).

Rates of larval deformities differed between the preliminary and main reproduction tests. Mean frequencies of deformities in larvae from the preliminary test generally increased with increasing Se exposure (from 4.3 percent in controls to 21 percent in Se-5; fig. 12). Frequencies of deformities were lower for the older (14-dpf) larvae from the main reproduction study, with a maximum frequency of 10.1 percent in treatment $\mathrm{Se}-4$ (fig. 12). Analysis of the combined larval deformity data by rank ANOVA indicated significant differences in the frequency of deformities between the preliminary and main reproduction studies $(\mathrm{p}<0.0001)$, but no differences among Se treatments $(\mathrm{p}=0.13)$. Yolk-sac larvae collected during the preliminary study had greater frequencies of deformities in Se treatments (43-74 percent), but these small samples (282 fish) were not included in statistical analyses.

Rates of deformities of pupfish larvae in this study were generally lower than those reported for other warm-water fishes under similar exposure scenarios. Bluegill larvae of parents exposed to 13 or $30 \mu \mathrm{g} / \mathrm{g}$ dietary Se had similar types of deformities but at greater deformity rates ( 50 percent and 100 percent, respectively), although the rates of deformities in individual replicates varied widely (from 3 percent to 100 percent) at the lower Se exposure level (Woock and others, 1987). Hermanutz and others (1992) reported lordosis in 11.6 percent of bluegill larvae hatched from eggs containing $4.4 \mu \mathrm{g} / \mathrm{g}$ Se, compared to our finding of lordosis in less than 5.2 percent of pupfish larvae from eggs with similar Se concentrations.

Differences in the frequency of deformities between larvae from the preliminary and main reproduction studies may reflect differences in the time of egg collections, relative to the onset of spawning. Eggs from the preliminary reproductive study were collected shortly (1-9 days) after spawning groups were isolated, whereas spawns used to characterize deformities in the main reproduction test were collected at least 14 days after the onset of spawning. Larvae produced early in the spawning period could have experienced greater Se exposure, because of a longer period of exposure in ovo and greater initial ovary-Se concentrations. The hypothesis of greater Se exposure for the first eggs produced by adult pupfish is consistent with the gradual decrease in Se concentrations with time in the three composite egg samples collected for analysis during the main reproduction study.

Deformities were rarely observed in juvenile pupfish. Only one abnormality (curved rays in the dorsal fin) was 


\section{A. Larvae from two reproduction studies}

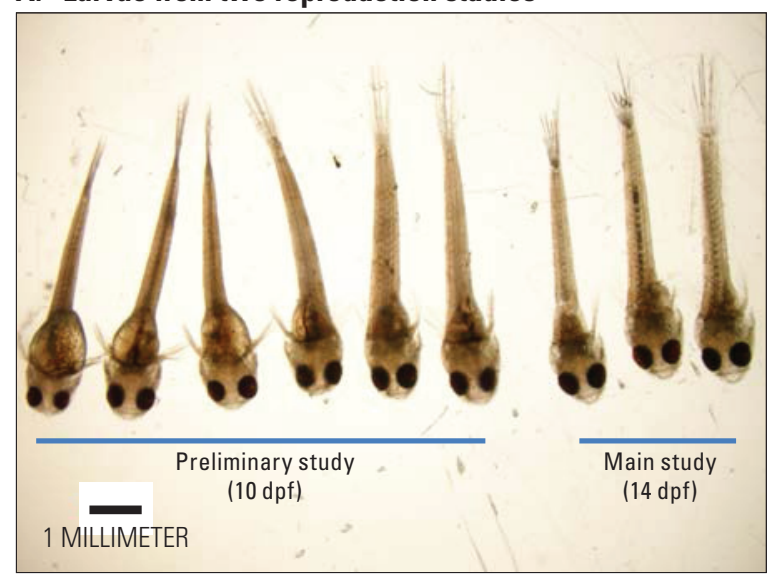

\section{Deformed larva from Se-3 treatment}

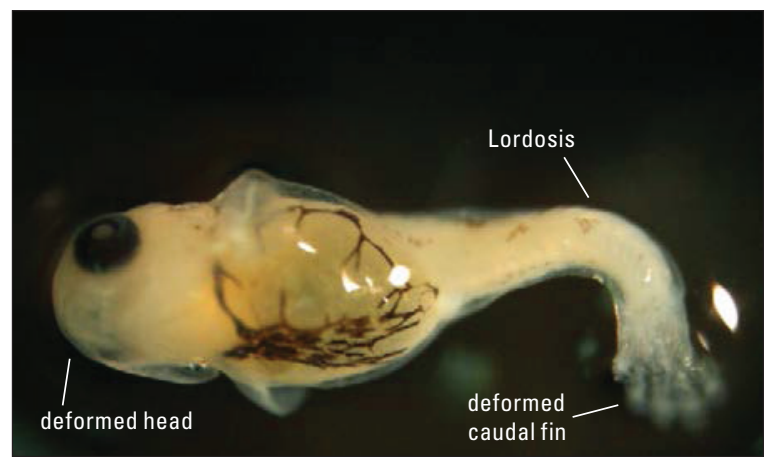

Figure 11. Normal and deformed pupfish larvae.

\section{B. Normal larvae from control treatment}

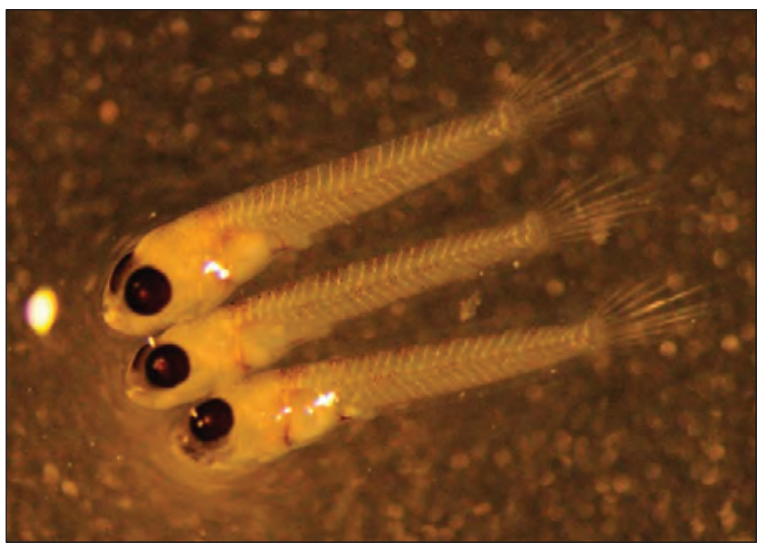

D. Deformed larva from Se-4 treatment

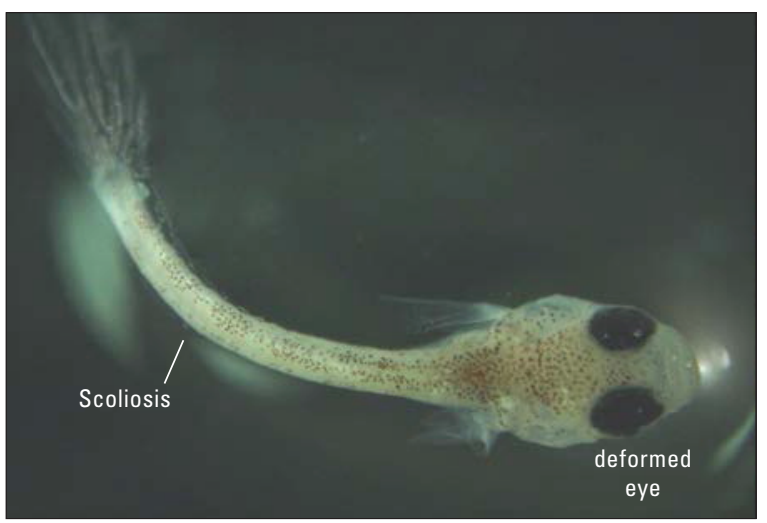

Table 8. Relative frequency of types of deformities observed in F1 pupfish larvae.

[Frequency of each deformity type relative to the total number of deformities, expressed as percent. Delay, delayed development]

\begin{tabular}{|c|c|c|c|c|c|c|c|c|}
\hline Study & $\begin{array}{c}\text { Number } \\
\text { of fish }\end{array}$ & $\begin{array}{l}\text { Lordosis } \\
\text { (percent) }\end{array}$ & $\begin{array}{l}\text { Scoliosis } \\
\text { (percent) }\end{array}$ & $\begin{array}{c}\text { Eye } \\
\text { (percent) }\end{array}$ & $\begin{array}{c}\text { Craniofacial } \\
\text { (percent) }\end{array}$ & $\begin{array}{c}\text { Fin } \\
\text { (percent) }\end{array}$ & $\begin{array}{c}\text { Edema } \\
\text { (percent) }\end{array}$ & $\begin{array}{c}\text { Delay } \\
\text { (percent) }\end{array}$ \\
\hline $\begin{array}{l}\text { Preliminary } \\
\text { study }\end{array}$ & 1,069 & 88.4 & 8.8 & 0.9 & 0 & 1.9 & 0 & 0 \\
\hline Main study & 1,376 & 68.6 & 12.9 & 7.1 & 1.4 & 8.6 & 0 & 1.4 \\
\hline
\end{tabular}

observed in 90 juveniles examined after day 58 (72 dpf) of the F1 exposure. The absence of abnormalities in $F 1$ juveniles suggests that either deformed larvae died before $72 \mathrm{dpf}$ or they recovered from the deformities observed during larval stages. Mortality rates for F1 larvae (5-15 percent) were generally greater than deformity rates, suggesting that some of the deformities could have contributed to juvenile mortality. Larvae from treatment $\mathrm{Se}-5$ had a deformity rate of 6.5 percent and a larval mortality rate of 16 percent (through $21 \mathrm{dph}$ ), followed by a juvenile mortality rate of 12 percent (21-72 dph). However, few larval or juvenile mortalities were observed in other treatment groups, despite deformity rates up to 10 percent (in Se-4), suggesting that some deformed F1 pupfish recovered as they developed. Lordosis at early developmental stages, the most common skeletal deformity observed in Se-exposed pupfish, has been reported to lessen or disappear with continued development in otherwise normal fish (Kayim and others, 2010; Moretti, 2005). This hypothesis also is consistent with the decrease in the frequency of deformities between younger larvae (about $10 \mathrm{dpf}$ ) from the preliminary reproduction study and the older (14 dpf) larvae from the main reproduction study (table 8). 


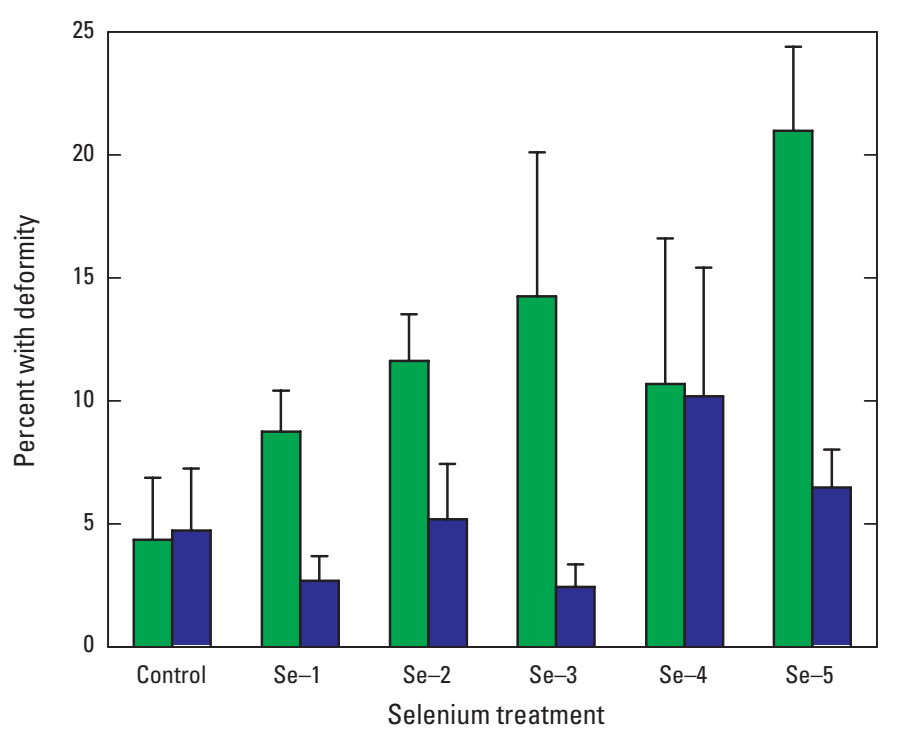

EXPLANATION

[Means and standard errors of 4-6 samples from the preliminary study and 12-16 samples from the main study]

$\square$ Preliminary study

Main study

I Standard error

Figure 12. Frequency of deformities in pupfish larvae from preliminary and main reproduction studies.

\section{Conclusions}

Oligochaetes accumulated selenium from selenized yeast in a dose-dependent fashion with no toxic effects occurring at environmentally realistic selenium levels.-In most treatments, selenium (Se) uptake by oligochaetes was rapid and bioaccumulation increased in proportion to yeast rations and yeast Se concentrations. Oligochaete biomass remained stable or increased at tissue Se concentrations $(232 \mu \mathrm{g} / \mathrm{g})$ about 10 times greater than Se concentrations reported in invertebrates from pupfish habitats (table 1; Saiki and others, 2010, 2011a). Oligochaete biomass decreased at tissue Se concentrations of $274 \mu \mathrm{g} / \mathrm{g}$ or greater. Repeated subsampling of Sedosed oligochaetes from large batches in long-term exposures (28 days or longer) resulted in less variable tissue Se concentrations, compared to repeated short-term (7-day) exposures. These results were the basis for the exposure protocol for dosing oligochaetes for pupfish feeding studies: 28 days of feeding of a low-ration (1.25 percent) of Se-dosed yeast to large batches (50 g wet weight) of oligochaetes. Oligochaete diets for pupfish exposures were prepared at five Se dosing levels to approximate a 50-percent dilution series, with mean measured tissue Se concentrations ranging from $5.1 \mu \mathrm{g} / \mathrm{g}$ to $52 \mu \mathrm{g} / \mathrm{g}$ (dry weight basis). Nutritional characteristics of oligochaete diets were consistent across the full range of Se dose levels.

Juvenile pupfish accumulated selenium rapidly from selenium-dosed oligochaetes and reached stable whole-body selenium concentrations before sexual maturity.-Adult pupfish accumulated whole-body Se concentrations ranging from 26 percent to 45 percent of Se concentrations in their oligochaete diets. Selenium concentrations in eggs and F1 juveniles were similar to or slightly greater than in F0 adults. The SeMet fraction of total Se in pupfish tissues (69-72 percent SeMet) was greater than in Se-dosed oligochaete diets (27-36 percent SeMet). Enrichment of SeMet in the simplified laboratory food chain was greater than SeMet fractions reported for Secontaminated pupfish habitats (for example, 52 percent SeMet in wild pupfish; Saiki and others, 2011c).

Selenium exposure had minimal effects on survival or growth of juvenile or adult pupfish.-There were no significant differences in pupfish survival or growth among treatments. However, growth and survival did show evidence of toxic effects (reductions of 10 percent or more, compared to controls) on multiple sampling dates (table 9). These effects were most consistent in pupfish in the highest Se treatment (Se-5), which had reduced growth of F0 juveniles on day 56 (17 percent less than controls) and of F1 juveniles on day 30 (21 percent less than controls). These growth reductions did not persist to subsequent sampling dates, but reduced growth of F1 pupfish in the Se-5 treatment on day 30 was followed by a reduction in survival ( 12 percent less than controls) in this treatment on day 58. This pattern of reduced growth and survival suggests that pupfish in the $\mathrm{Se}-5$ treatment were at or near the threshold for chronic Se toxicity.

Pupfish egg production was reduced substantially in most selenium treatments, compared to controls.-There was no statistically significant overall effect of Se treatment on pupfish egg production during the reproduction study, reflecting variation among replicates and among sampling dates. However, egg production was greatest in the control group and all Se treatments except $\mathrm{Se}-1$ had reductions in egg production ranging from 24 percent in $\mathrm{Se}-5$ to 51 percent in $\mathrm{Se}-4$ (table 9). Comparison of daily mean egg production (eggs per replicate) for 23 sampling dates indicated that egg production in each of the Se treatments was significantly less than controls on multiple (3-7) sampling dates. These results suggest that pupfish egg production was adversely affected by elevated Se exposure, although these trends were partially obscured by variation within treatments. The variability of egg production in this study suggests that changes in experimental design, such as a larger number of spawning groups or a different arrangement of spawning adults (for example, 1 male and 1 female per chamber) may be necessary to achieve statistical power adequate to detect biologically significant differences in egg production among treatments.

Egg hatching, larval survival, and larval deformities provided little evidence of selenium toxicity.-Egg hatching and larval survival in all Se treatments were within 10 percent of control means and differences among treatments were not related to Se exposure (table 9), although the Se-5 treatment had lowest larval survival ( 84 percent) and lowest combined egg hatching and larval survival to $21 \mathrm{dpf}$ (76 percent). Frequencies of deformities in F1 larvae generally increased with 
Table 9. Summary of pupfish toxicity endpoints and selenium exposure levels.

[Cell borders indicate toxicity endpoints with 10 percent or greater reduction, relative to controls. Toxicity thresholds (indicated by colored highlights) are the lowest selenium concentrations associated with consistent reductions of 10 percent or greater on survival and growth (yellow) or reproduction (pink). Se, selenium; F0, first generation (parents); F1, second generation (offspring); dpf, days post-fertilization]

\begin{tabular}{|c|c|c|c|c|c|}
\hline Endpoint & Se-1 & Se-2 & $\mathrm{Se}-3$ & Se-4 & Se-5 \\
\hline \multicolumn{6}{|c|}{ Growth and survival (percent difference from control) } \\
\hline F0 growth (day 28 ) & -3 & -4 & -7 & 0 & -4 \\
\hline F0 growth (day 56) & -2 & -9 & -12 & -5 & -17 \\
\hline F0 growth (day 85 ) & 7 & 1 & 0 & -2 & 13 \\
\hline F0 growth (day 150) & 3 & 3 & 2 & -3 & -7 \\
\hline F0 survival (day 28) & 0 & 0 & 0 & 0 & 0 \\
\hline F0 survival (day 150) & 3 & 3 & 3 & 0 & 7 \\
\hline F1 growth (day 30) & 0 & 4 & 8 & 6 & -21 \\
\hline F1 growth (day 58) & 2 & 10 & 10 & 11 & -2 \\
\hline F1 survival (day 30) & 0 & 0 & 0 & -3 & -3 \\
\hline F1 survival (day 58) & 0 & -8 & -10 & -5 & -13 \\
\hline Larval deformities (14 dpf) & 2 & -1 & 2 & -5 & -2 \\
\hline Larval survival (21 dpf) & 8 & 2 & 6 & 7 & -7 \\
\hline \multicolumn{6}{|c|}{ Selenium exposure (micrograms per gram dry weight) } \\
\hline Diet Se & 5.1 & 7.3 & 14 & 24 & 52 \\
\hline Whole-body Se & 3.0 & 3.6 & 6.7 & 12 & 28 \\
\hline Egg Se & 3.0 & 4.4 & 8.0 & 13 & 27 \\
\hline
\end{tabular}

increasing parental Se exposure, but differences among Se treatments were not statistically significant.

Pupfish responses to elevated Se exposure were not typical of responses of other freshwater fishes.-Apparent toxicity thresholds for survival and growth of pupfish from larvae through adults $(52 \mu \mathrm{g} / \mathrm{g}$ for dietary Se and $28 \mu \mathrm{g} / \mathrm{g}$ for whole-body Se; table 9) indicate that pupfish were among the least-sensitive freshwater fish for these endpoints. In contrast, pupfish egg production was reduced in all Se treatments with egg Se concentrations of $4.4 \mu \mathrm{g} / \mathrm{g}$ or greater (table 9), well below the range of reproductive chronic values reported for other freshwater fish (17-24 $\mu \mathrm{g} / \mathrm{g}$ in eggs) (Janz and others, 2010). The most sensitive reproductive endpoints for Se toxicity to other fish species are typically larval deformities or larval mortality, rather than egg production. The unusual sensitivity of the egg production endpoint and the statistical ambiguity of the egg production data suggest that more study is needed to document the effect of Se exposure on pupfish egg production.

Pupfish egg production, but not survival or growth, may be adversely affected by selenium exposure in some Imperial Valley habitats.-Midge tissues represent a conservative (worst-case) basis for comparison with pupfish dietary toxicity thresholds because midges had the greatest average Se concentrations and greatest SeMet fraction of pupfish diet components in the Imperial Valley (table 1). Midge Se concentrations for all seven sites in the Imperial Valley sampled in 2006-2008 (table 1) (Saiki and others, 2010, 2011a) were less than the dietary threshold for reduced survival or growth $(52 \mu \mathrm{g} / \mathrm{g})$, but midge Se concentrations from two of these sites exceeded the dietary threshold for reduced egg production $(7.3 \mu \mathrm{g} / \mathrm{g})$. Whole-body Se concentrations measured recently (2006-2009) in pupfish and sailfin molly (Poecilia latipinna), a potential bioaccumulation surrogate for pupfish, provide a more direct measure of pupfish Se exposure at sites in the Imperial Valley (Saiki and others, 2011c). Mean whole-body Se concentrations in pupfish and sailfin mollies from all sites sampled (table 1) were less than the whole-body toxicity threshold for pupfish survival and growth $(28 \mu \mathrm{g} / \mathrm{g})$, but greater than the threshold for pupfish egg production $(3.6 \mu \mathrm{g} / \mathrm{g})$.

Limited data on pupfish populations in the Imperial Valley do not indicate adverse effects of elevated selenium exposure.-Pupfish were found at all seven intensive study sites during the 2006-2008 study and pupfish population densities were not clearly related to whole-body Se concentrations in midges or sailfin mollies (Saiki and others, 2010). Although pupfish population estimates may reflect biases such as differences in sampling efficiency among sites and movement of pupfish among locations with differing Se exposure levels, the available data suggests that pupfish make up a small, but variable, component of fish communities in Imperial Valley habitats, including Se-contaminated areas. 
Pupfish may be able to maintain populations in habitats affected by selenium contamination and other environmental stressors. - Martin and Saiki (2005) reported that occurrence of pupfish in the Salton Sea area was associated positively with environmental extremes, including high salinity, high $\mathrm{pH}$, and low dissolved oxygen, perhaps reflecting avoidance of competition and predation by non-native fish species. Varela-Romero and others (2002) also reported use of marginal habitats by pupfish in the Colorado River delta in Mexico and concluded that maintenance of viable pupfish populations in these habitats was dependent on re-colonization and dispersal. Saiki and others (2011b) documented opportunistic colonization by pupfish of experimental ponds in the Salton Sea basin. The current study suggests that pupfish reproduction may be reduced in Se-contaminated habitats, but also demonstrates that juvenile and adult pupfish can tolerate high levels of Se exposure, which may allow repopulation of affected areas.

\section{References Cited}

American Public Health Association, American Waste Water Association, and Water Environment Foundation, 2005, Standard methods for the examination of water and wastewater, (21st ed.): Alexandria Virginia, American Public Health Association, 1,368 p.

Besser, J.M., Canfield, T.J., and La Point, T.W., 1993, Bioaccumulation of organic and inorganic selenium in a laboratory food chain: Environmental Toxicology and Chemistry, v. 12 , p. 57-92.

Besser, J.M., Greer, I.E., Kunz, J.L., Ingersoll, C.G., and Wang, N., 2004, Development of Methods for Laboratory Culture and Toxicity Testing of the Endangered Desert Pupfish, Cyprinodon macularius, and Evaluation of the Acute Toxicity of Selenium, Final Report to the US Fish and Wildlife Service, Carlsbad, California: Columbiaa Missouri, U.S. Geological Survey.

Conover, W.J., and Iman, R.L., 1981, Rank transformations as a bridge between parametric and nonparametric statistics: American Statistician, v. 35, p. 124-129.

Coyle, J.J., Buckler, D.R., Ingersoll, C.G., Fairshild, J.F., and May, T.W., 1991, Effect of dietary selenium on the reproductive success of bluegills (Lepomis macrochirus): Environmental Toxicology and Chemistry, v. 12, p. 551-565.

DeForest, D., Brix, K.V., and Adams, W.J., 1999, Critical review of proposed residue-based selenium toxicity thresholds for freshwater fish: Human and Ecological Risk Assessment, v. 5, p. 1,188-1,228.
DeForest, D.K., and Adams, W.J., 2011, Selenium bioaccumulation and toxicity in freshwater fishes, in Beyer, W.N., and Meador, J.P., eds., Environmental Contaminants in BiotaInterpreting Tissue Concentrations, (2nd ed.): Boca Raton, Fla., CRC Press/Taylor and Francis, p. 193-230.

Fan, T., Teh, S., Hinton, D., and Higashi, R., 2002, Selenium biotransformations in to proteinaceous forms by foodweb organisms of selenium-laden drainage waters in California: Aquatic Toxicology, v. 57, p. 65-84.

Gerking, S.D., and Lee, R.M., 1980, Reproductive performance of the desert pupfish (Cyprinodon n. nevadensis) in relation to salinity: Environmental Biology of Fishes, v. 5, no. 4 , p. 375-378.

Hamilton, S.J., Buhl, K.J., Faerber, N.L., Weidmeyer, R.H., and Bullard, F.A., 1990, Toxicity of organic selenium in the diet to chinook salmon: Environmental Toxicology and Chemistry, v. 9, p. 347-358.

Hamilton, S.J., Holley, K.M., Buhl, K.J., Bullard, F.A., Weston, L., and McDonald, S., 2002, Toxicity of selenium and other elements in food organisms to razorback sucker larvae: Aquatic Toxicology, v. 59, p. 253-281.

Hermanutz, R.O., Allen, K.N., Roush, T.H., and Hedtke, S.F., 1992, Effects of elevated selenium concentrations on bluegills (Lepomis macrochirus) in outdoor experimental streams: Environmental Toxicology and Chemistry, v. 11, p. 217-224.

Holm, J., Palace, V.P., Siwik, P., Sterling, G., Evans, R., Baron, C., Werner, J., and Wautier, K., 2005, Developmental effects of bioaccumulated selenium in eggs and larvae of two salmonid species: Environmental Toxicology and Chemistry, v. 24, p. 2,373-2,381.

Janz, D.M., DeForest, D.K., Brooks, M., Chapman, P.M., Gilron, G., Hoff, D., Hopkins, W., McIntyre, D., Mebane, C.A., Palace, V., Skorupa, J.P., and Wayland, M., 2010, Selenium toxicity to aquatic organisms, in Chapman, P.M., Adams, W.J., Brooks, M.L., Delos, C.G., Luoma, S.N., Maher, W.A., Ohlendorf, H.M., Presser, T.S., and Shaw, D.P., eds., Ecological assessment of selenium in the aquatic environment: Pensacola, Fla., SETAC Press, p. 141-231.

Kayim, M., Can, E., and Guner, Y., 2010, Is it possible to transform hatchery-reared abnormal juveniles of sea bass (Dicentrachus labrax I., 1758) into normal individuals?: Asian Journal of Animal and Veterinary Advances, v. 5, p. 327-338.

Lee, R., and Gerking, S., 1980, Survival and reproductive performance of the desert pupfish, Cyprinodon n. nevadensis (Eigenmann and Eigenmann), in acid waters: Journal of Fish Biology, v. 17, no. 5, p. 507-515. 
Lemly, A.D., 1993a, Guidelines for evaluating selenium data from aquatic monitoring and assessment studies: Environmental Monitoring and Assessment, v. 28, p. 83-100.

Lemly, A.D., 1993b, Metabolic stress during winter increases the toxicity of selenium to fish: Aquatic Toxicology, v. 27, p. $133-158$.

Lemly, A.D., 1993c, Teratogenic effects of selenium in natural populations of freshwater fish: Ecotoxicology and Environmental Safety, v. 26, p. 181-204.

Martin, B.A., and Saiki, M.K., 2005, Relation of desert pupfish abundance to selected environmental variable in natural and manmade habitats in the Salton Sea basin: Environmental Biology of Fishes, v. 73, p. 97-107.

May, T.W., Walther, M.J., Saiki, M.K., and Brumbaugh, W.G., 2009, Total selenium and selenium species in irrigation drain Inflows to the Salton Sea, California, October 2008 and January 2009: U.S. Geological Survey Open-File Report 2009-1123.

McIntyre, D.O., Pacheco, M.A., Garton, M.W., Wallschlager, D., and Delos, C.G., 2008, Effect of selenium on juvenile bluegill sunfish at reduced temperature, EPA822-R-08-020. : Washington, D.C., U.S. Environmental Protection Agency, Office of Water.

Moretti, A., Fernandez-Criado, M.P., and Vetillart, R., 2005, Manual on hatchery production of seabass and gilthead seabream, Vol. 2: Rome, Food and Agriculture Organization of the United Nations, $152 \mathrm{p}$.

Mount, D.R., Highland, T.L., Mattson, V.R., Dawson, T.D., Lott, K.G., and Ingersoll, C.G., 2006, Use of the oligochaete, Lumbriculus variegatus, as a prey organisms for toxicant exposure of fish through the diet: Environmental Toxicology and Chemistry, v. 25, no. 10, p. 195-202.

Muscatello, J.R., Bennett, P.M., Himbeault, K.T., Andrew, M., and Janz, D.M., 2006, Larval deformities associated with selenium accumulation in northern pike (Esox lucius) exposed to metal mining effluent: Environmental Science and Technology, v. 40, no. 20, p. 6,506-6,512.

Ogle, R.S., and Knight, A.W., 1989, Effects of elevated foodborne selenium on growth and reproduction of the fathead minnow (Pimephales promelas): Archives of Environmental Contamination and Toxicology, v. 18, p. 795-803.

Saiki, M.K., Martin, B.A., and May, T.W., 2010, Final Report: Baseline selenium monitoring of agricultural drains operated by the Imperial Irrigation District in the Salton Sea Basin, California: U.S. Geological Survey Open-File Report 2010-1064, p. 100.

Saiki, M.K., Martin, B.A., and May, T.W., 2011a, Selenium in aquatic biota inhabiting agricultural drains in the Salton Sea Basin, California: Environmental Monitoring and Assessment, 18 p. (Also available at $h t t p: / / d x$.doi.org/10.1007/ s10661-011-2367-1.)
Saiki, M.K., Martin, B.A., and Anderson, T.W., 2011b, unusual dominance by desert pupfish (Cyprinodon macularius) in experimental ponds within the Salton Sea Basin: The Southwestern Naturalist, v. 56, no. 3, p. 385-392.

Saiki, M.K., Martin, B.A., and May, T.W., 2011c, Assessment of western mosquitofish and sailfin mollies as surrogate species for monitoring selenium exposure in desert pupfish inhabiting agricultural drains: Water, Air, and Soil Pollution, 13 p. (Also available at http://dx.doi.org/10.1007/s11270011-0974-7.)

Saiki, M.K., and Ogle, R.S., 1995, Evidence of impaired reproduction by western mosquitofish inhabiting seleniferous drainwater: Transactions of the American Fisheries Society, v. 124, p. 578-587.

Shrode, J.B., and Gerking, S.D., 1977, Effects of constant and fluctuating temperatures on reproductive performance of a desert pupfish, Cyprinodon n. nevadensis: Physiological Zoology, v. 50, no. 1, p. 1-10.

Sorensen, E.M.B., 1988, Selenium accumulation, reproductive status, and histopathological changes in environmentally exposed redear sunfish: Archives of Toxicology, v. 61, no. 4, p. 324-329.

Sorensen, E.M.B., Cumbie, P.M., Bauer, T.L., Bell, J.S., and Harlan, C.W., 1984, Histopathological, hematological, condition-factor, and organ weight changes associated with selenium accumulation in fish from Belews Lake, North Carolina: Archives of Environmental Contamination and Toxicology, v. 13, p. 153-162.

Teh, S., Deng, X., Teh, F.-C., and Hung, S., 2002, Selenium-induced teratogenicity in Sacramento splittail (Pogonichthys macrolepidotus): Marine and Freshwater Research, v. 54, p. 605-608.

U.S. Environmental Protection Agency, 2000, Methods for measuring the toxicity and bioaccumulation of sedimentassociated contaminants with freshwater invertebrates, EPA/600/R-99/064: Duluth, Minn., U.S. Environmental Protection Agency, $133 \mathrm{p}$.

Varela-Romero, A., Ruiz-Campos, G., Yépiz-Velázquez, L.M., and Alaníz-García, J., 2002, Distribution, habitat and conservation status of desert pupfish (Cyprinodon macularius) in the Lower Colorado River Basin, Mexico: Reviews in Fish Biology and Fisheries, v. 12, no. 2, p. 157-165.

Wan, L., 2007, Determination of total selenium and selenoamino acids in yeast and aquatic organisms by liquid chromatography and inductively-coupled plasma mass spectrophotometry.: Columbia, Mo., University of Missouri, 140 p.

Woock, S.E., Garrett, W.R., Partin, W.E., and Bryson, W.T., 1987, Decreased survival and teratogenesis during laboratory selenium exposures to bluegill, Lepomis macrochirus: Bulletin of Environmental Contamination and Toxicology, v. 39, p. $998-1,005$. 
Appendix Tables A-E 
Appendix A. Test conditions for dosing oligochaete diets with selenium.

$\left[{ }^{\circ} \mathrm{C}\right.$, degrees Celsius; L, liter; mg/L, milligram per liter; g, gram; Se, selenium; $\mu \mathrm{g} / \mathrm{g}$, microgram per gram]

\begin{tabular}{|c|c|}
\hline Test Condition & Description \\
\hline General test conditions & Same as appendix B (unless noted below). \\
\hline Water temperature & $23^{\circ} \mathrm{C}$. \\
\hline Test chambers & 7-L all-glass aquaria (6 L water volume). \\
\hline Test water & Well water (hardness $280 \mathrm{mg} / \mathrm{L}$ as calcium carbonate). \\
\hline Water replacement & $\begin{array}{l}24 \text { diluter cycles per day ( } 1 \text { volume/day). Replacement rate will be increased if } \\
\text { necessary to prevent depletion of dissolved oxygen or build up of ammonia. }\end{array}$ \\
\hline Test organism & Oligochaete (Lumbriculus variegatus). \\
\hline Stocking rate & $50 \mathrm{~g}$ (wet weight) oligochaetes per chamber. \\
\hline Aqueous Se exposure & None. \\
\hline \multirow[t]{7}{*}{ Selenized yeast diets } & $\begin{array}{l}\text { Mixtures of selenized yeast (Selenosource 600) and control yeast (Red Star }{ }^{\mathrm{TM}} \\
\text { nutritional yeast). }\end{array}$ \\
\hline & Control: 100 percent control yeast (measured Se: $0.27 \mu \mathrm{g} / \mathrm{g}$ dry weight). \\
\hline & Se-1: 1 percent Se-yeast; nominal $\mathrm{Se}=6.2 \mu \mathrm{g} / \mathrm{g}$. \\
\hline & Se-2: 2 percent Se-yeast; nominal $\mathrm{Se}=13 \mu \mathrm{g} / \mathrm{g}$. \\
\hline & Se-3: 4 percent Se-yeast; nominal $\mathrm{Se}=25 \mu \mathrm{g} / \mathrm{g}$. \\
\hline & $\mathrm{Se}-4$ : 8 percent Se-yeast; nominal $\mathrm{Se}=50 \mu \mathrm{g} / \mathrm{g}$. \\
\hline & $\mathrm{Se}-5$ : 16 percent Se-yeast; nominal $\mathrm{Se}=100 \mu \mathrm{g} / \mathrm{g}$. \\
\hline Ration & 1.25 percent (dry weight/wet weight) daily: $0.625 \mathrm{~g}$ dry yeast/chamber/day. \\
\hline Dosing period & Minimum 28 days. \\
\hline Dosing schedule & $\begin{array}{l}\text { One or more chambers per dose level stocked weekly, starting } 28 \text { days before } \\
\text { start of Phase-1 pupfish exposure. }\end{array}$ \\
\hline \multirow[t]{2}{*}{ Water-quality monitoring } & Temperature, dissolved oxygen, $\mathrm{pH}$, ammonia, (weekly). \\
\hline & Salinity, total alkalinity, total hardness (monthly). \\
\hline Harvest schedule & Daily harvest by wet weight; split visually among replicates. \\
\hline
\end{tabular}


Appendix B. Test conditions for life-cycle selenium exposure with desert pupfish.

$\left[{ }^{\circ} \mathrm{C}\right.$, degrees Celsius; L, liter; mg/L, milligram per liter; ASTM, ????; g/L, gram per liter; F0, parent generation; F1, offspring; dpf, days post-fertilization; Se, selenium; $\mu \mathrm{g} / \mathrm{L}$, microgram per liter; $\mu \mathrm{g} / \mathrm{g}$, microgram per gram; SeMet, selenomethionine]

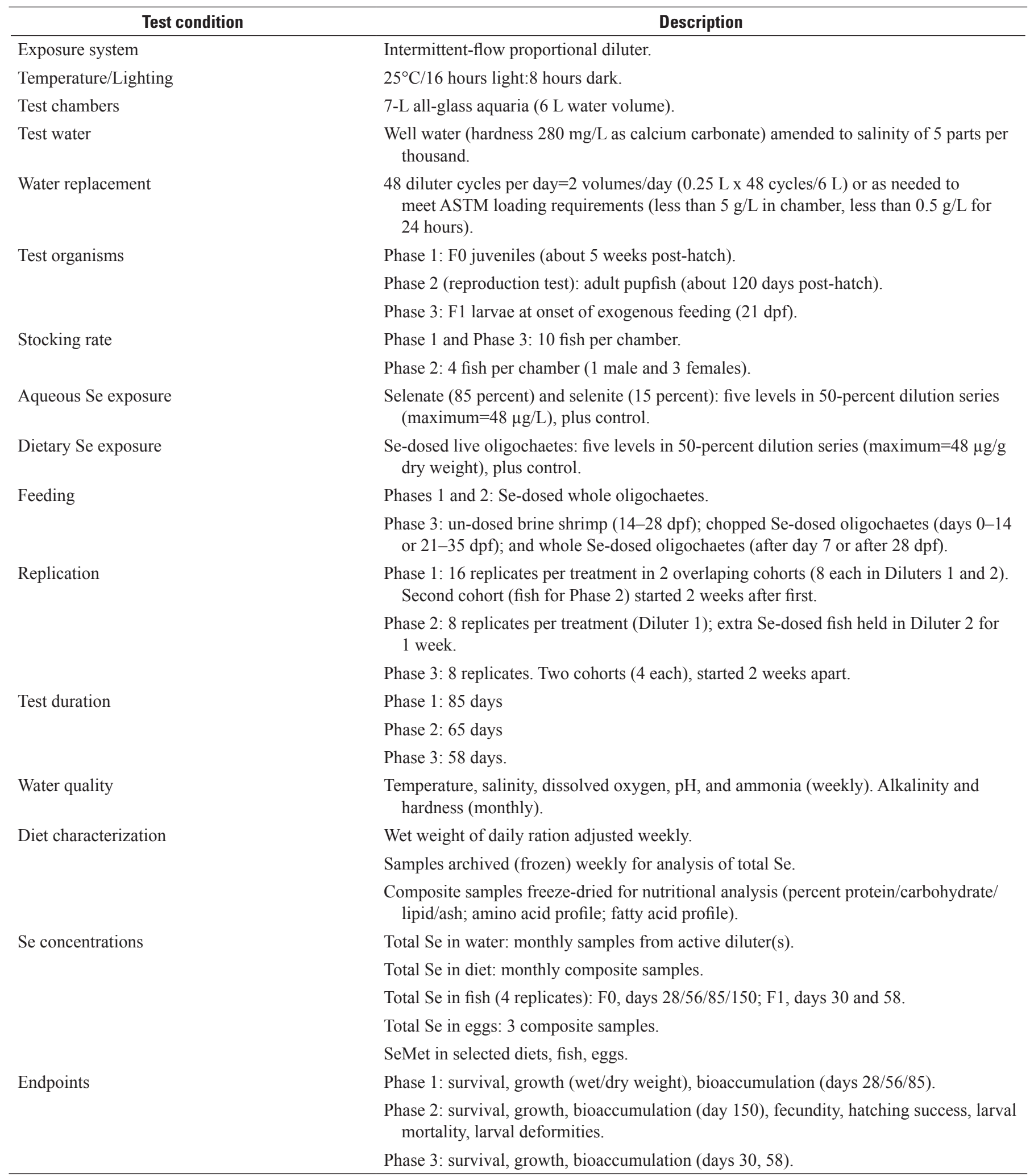


Appendix C. Nutritional characteristics of oligochaete diets from pupfish life-cycle exposures.

[One composite per treatment, with overall mean and standard deviation (STD). Se, selenium; nd, not detected]

\begin{tabular}{|c|c|c|c|c|c|c|c|c|}
\hline \multirow{2}{*}{ Analyte } & \multicolumn{6}{|c|}{ Treatments } & \multirow{2}{*}{ Mean } & \multirow{2}{*}{ STD } \\
\hline & Control & $\mathrm{Se}-1$ & $\mathrm{Se}-2$ & $\mathrm{Se}-3$ & Se-4 & $\mathrm{Se}-5$ & & \\
\hline \multicolumn{9}{|c|}{ Calories (per 100 grams) } \\
\hline \multicolumn{9}{|c|}{ Proximate analysis (percent) } \\
\hline Protein & 60 & 58 & 57 & 56 & 57 & 56 & 57 & 1.3 \\
\hline Carbohydrate & 19 & 22 & 25 & 24 & 25 & 23 & 23 & 2.3 \\
\hline Moisture & 6.2 & 6.1 & 5.6 & 5.9 & 5.0 & 6.6 & 5.9 & .6 \\
\hline \multicolumn{9}{|c|}{ Amino acids (percent) } \\
\hline TRY & 0.8 & 0.8 & 0.8 & 0.8 & 0.8 & 0.8 & 0.8 & 0 \\
\hline CYS & .6 & .7 & .7 & .7 & .6 & .7 & .7 & 0 \\
\hline MET & 1.0 & 1.1 & 1.1 & 1.1 & 1.1 & 1.1 & 1.1 & 0 \\
\hline ASP & 5.9 & 5.9 & 5.7 & 5.9 & 5.8 & 5.8 & 5.9 & .1 \\
\hline ALA & 3.3 & 3.1 & 3.1 & 3.2 & 3.1 & 3.3 & 3.2 & .1 \\
\hline VAL & 2.9 & 3.0 & 2.8 & 2.9 & 2.8 & 2.8 & 2.8 & .1 \\
\hline ISO & 2.6 & 2.7 & 2.7 & 2.8 & 2.7 & 2.7 & 2.7 & .1 \\
\hline LEU & 4.6 & 4.6 & 4.4 & 4.6 & 4.5 & 4.5 & 4.5 & .1 \\
\hline TYR & 1.8 & 1.7 & 1.6 & 1.6 & 1.7 & 1.6 & 1.7 & .1 \\
\hline PHE & 2.7 & 2.8 & 2.7 & 2.7 & 2.7 & 2.7 & 2.7 & 0 \\
\hline LYS & 4.5 & 4.5 & 4.4 & 4.5 & 4.4 & 4.3 & 4.4 & .1 \\
\hline HIS & 1.4 & 1.5 & 1.4 & 1.5 & 1.5 & 1.5 & 1.5 & 0 \\
\hline ARG & 4.0 & 3.6 & 3.7 & 3.8 & 3.7 & 3.6 & 3.7 & .1 \\
\hline \multicolumn{9}{|c|}{ Fatty acids (percent) } \\
\hline $\mathrm{C} 080$ & nd & $\mathrm{nd}$ & $\mathrm{nd}$ & nd & nd & nd & -- & -- \\
\hline $\mathrm{C} 100$ & 0.01 & 0.01 & 0.01 & 0.01 & 0.01 & 0.01 & 0.01 & 0 \\
\hline $\mathrm{C} 170$ & .08 & .07 & .07 & .07 & .07 & .07 & .07 & 0 \\
\hline $\mathrm{C} 171$ & nd & .01 & nd & nd & nd & nd & .01 & -- \\
\hline $\mathrm{C} 180$ & .31 & .25 & .28 & .29 & .32 & .30 & .29 & .02 \\
\hline $\mathrm{C} 181$ & .86 & .64 & .72 & .73 & .72 & .69 & .73 & .07 \\
\hline C182 & .17 & .16 & .15 & .16 & .17 & .16 & .16 & .01 \\
\hline $\mathrm{C} 183$ & .07 & .07 & .06 & .07 & .08 & .07 & .07 & .01 \\
\hline $\mathrm{C} 184$ & .01 & nd & nd & .01 & nd & nd & .01 & 0 \\
\hline $\mathrm{C} 200$ & .02 & .01 & .02 & .02 & .02 & .02 & .02 & 0 \\
\hline C201 & .44 & .42 & .43 & .46 & .46 & .44 & .44 & .02 \\
\hline C202 & .30 & .33 & .33 & .34 & .35 & .33 & .33 & .02 \\
\hline C203 & .07 & .09 & .08 & .09 & .09 & .06 & .08 & .01 \\
\hline C204 & .24 & .30 & .27 & .28 & .27 & .26 & .27 & .02 \\
\hline $\mathrm{C} 205$ & .39 & .39 & .40 & .46 & .51 & .45 & .43 & .05 \\
\hline $\mathrm{C} 215$ & .01 & .01 & .01 & .01 & .01 & .01 & .01 & 0 \\
\hline $\mathrm{C} 220$ & .03 & .02 & .02 & .02 & .02 & .03 & .02 & .01 \\
\hline $\mathrm{C} 221$ & .01 & .01 & .01 & .01 & .01 & .01 & .01 & 0 \\
\hline $\mathrm{C} 222$ & nd & nd & nd & nd & nd & nd & -- & -- \\
\hline C223 & nd & nd & nd & nd & nd & nd & -- & -- \\
\hline $\mathrm{C} 224$ & .04 & .05 & .04 & .04 & .04 & .04 & .04 & 0 \\
\hline $\mathrm{C} 225$ & .06 & .06 & .07 & .08 & .09 & .08 & .07 & .01 \\
\hline $\mathrm{C} 226$ & .14 & .13 & .16 & .17 & .23 & .19 & .17 & .04 \\
\hline C240 & .01 & .01 & .01 & .02 & .02 & .02 & .02 & .01 \\
\hline $\mathrm{C} 241$ & nd & nd & nd & nd & nd & nd & -- & -- \\
\hline
\end{tabular}


Appendix D. Summary of water quality during pupfish life-cycle exposure.

[Means, minima (min), and maxima ( $\max )$ by phase; $\mathrm{g} / \mathrm{L}$, gram per liter; $\mathrm{mg} / \mathrm{L}$, milligram per liter]

\begin{tabular}{|c|c|c|c|c|c|c|c|c|c|}
\hline \multirow{2}{*}{ Treatment } & \multicolumn{3}{|c|}{ Phase 1 (8-13 samples) } & \multicolumn{3}{|c|}{ Phase 2 (4-9 samples) } & \multicolumn{3}{|c|}{ Phase 3 (3-6 samples) } \\
\hline & Mean & Min & Max & Mean & Min & Max & Mean & Min & Max \\
\hline \multicolumn{10}{|c|}{ Salinity (g/L) } \\
\hline $\mathrm{Se}-1$ & 4.96 & 4.49 & 5.25 & 4.78 & 4.61 & 4.93 & 4.79 & 4.38 & 5.06 \\
\hline $\mathrm{Se}-2$ & 4.98 & 4.49 & 5.42 & 4.79 & 4.61 & 5.08 & 4.80 & 4.40 & 5.11 \\
\hline $\mathrm{Se}-4$ & 4.96 & 4.47 & 5.23 & 4.80 & 4.61 & 5.07 & 4.81 & 4.44 & 5.04 \\
\hline $\mathrm{Se}-5$ & 4.94 & 4.44 & 5.22 & 4.84 & 4.61 & 5.19 & 4.77 & 4.42 & 5.05 \\
\hline \multicolumn{10}{|c|}{$\mathrm{pH}$} \\
\hline Control & 8.27 & 8.05 & 8.48 & 8.30 & 7.95 & 8.58 & 8.47 & 8.25 & 8.71 \\
\hline $\mathrm{Se}-1$ & 8.25 & 7.98 & 8.47 & 8.28 & 8.15 & 8.44 & 8.41 & 8.23 & 8.59 \\
\hline $\mathrm{Se}-5$ & 8.28 & 8.01 & 8.49 & 8.28 & 8.13 & 8.43 & 8.42 & 8.26 & 8.52 \\
\hline \multicolumn{10}{|c|}{ Alkalinity (mg/L as calcium carbonate) } \\
\hline Control & 268 & 240 & 370 & 258 & 222 & 284 & 240 & 194 & 302 \\
\hline $\mathrm{Se}-1$ & 262 & 240 & 280 & 261 & 254 & 270 & 241 & 228 & 266 \\
\hline $\mathrm{Se}-2$ & 258 & 240 & 268 & 266 & 254 & 280 & 233 & 224 & 242 \\
\hline $\mathrm{Se}-3$ & 259 & 240 & 270 & 258 & 218 & 290 & 217 & 186 & 262 \\
\hline $\mathrm{Se}-4$ & 260 & 240 & 272 & 260 & 252 & 270 & 252 & 234 & 270 \\
\hline $\mathrm{Se}-5$ & 260 & 240 & 270 & 261 & 248 & 270 & 242 & 232 & 252 \\
\hline $\mathrm{Se}-5$ & 927 & 750 & 1,130 & 830 & 710 & 950 & 1,065 & 1,010 & 1,120 \\
\hline \multicolumn{10}{|c|}{ Dissolved oxygen (mg/L) } \\
\hline Control & 6.9 & 5.1 & 8.9 & 6.6 & 4.2 & 8.3 & 7.6 & 7.1 & 8.1 \\
\hline $\mathrm{Se}-1$ & 6.5 & 4.4 & 8.6 & 6.2 & 4.0 & 8.2 & 7.6 & 7.0 & 8.2 \\
\hline Se-2 & 6.8 & 4.8 & 8.4 & 6.0 & 4.0 & 8.3 & 7.6 & 6.9 & 8.3 \\
\hline $\mathrm{Se}-3$ & 6.6 & 5.1 & 8.3 & 6.3 & 4.1 & 8.2 & 7.3 & 6.7 & 8.0 \\
\hline $\mathrm{Se}-4$ & 6.6 & 4.3 & 8.0 & 6.1 & 4.1 & 8.2 & 7.3 & 6.7 & 8.2 \\
\hline $\mathrm{Se}-5$ & 6.6 & 4.9 & 8.2 & 6.0 & 3.9 & 8.2 & 7.8 & 6.9 & 8.2 \\
\hline \multicolumn{10}{|c|}{ Total ammonia (mg/L as nitrogen) } \\
\hline Control & 0.15 & 0.09 & 0.29 & 0.20 & 0.11 & 0.30 & 0.24 & 0.10 & 0.33 \\
\hline $\mathrm{Se}-1$ & .14 & .09 & .21 & .49 & .10 & 2.91 & .22 & .10 & .29 \\
\hline Se-2 & .14 & .10 & .23 & .35 & .10 & 1.78 & .21 & .09 & .26 \\
\hline $\mathrm{Se}-3$ & .13 & .06 & .24 & .18 & .10 & .29 & .22 & .09 & .37 \\
\hline $\mathrm{Se}-4$ & .14 & .09 & .28 & .18 & .06 & .42 & .21 & .09 & .36 \\
\hline $\mathrm{Se}-5$ & .13 & .09 & .22 & .17 & .09 & .40 & .20 & .08 & .30 \\
\hline
\end{tabular}


Appendix E. Egg production by pupfish during the main reproduction study.

The Excel file can be accessed at http://pubs.usgs.gov/sir/2012/5033/downloads/appendix-e.xlsx.

Publishing support provided by:

Rolla Publishing Service Center

For more information concerning this publication, contact:

Director, USGS Columbia Environmental Research Center

4200 New Haven Road

Columbia, Missouri 65201

(573) 875-5399

Or visit the Columbia Environmental Research Center Web site at: http://www.cerc.usgs.gov/ 



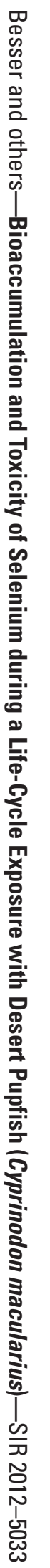

